\title{
DETECTORES MULTIUSUÁRIOS PARA DS/CDMA - LINEARES FIXOS
}

\author{
Taufik Abrão e Paul Jean E. Jeszensky
}

\begin{abstract}
Resumo - Este trabalho faz uma revisão dos principais detectores multiusuários (MUD) subótimos para sistemas DS-CDMA (Direct Sequence - Code Division Multiple Access). Nesta primeira parte são enfocados os detectores lineares fixos: Descorrelacionador e MMSE (Minimum Mean Square Error). Exploram-se os conceitos de Eficiência Assintótica Multiusuário (AME) e Resistência ao Efeito NearFar (NFRes), comparando-se o desempenho destes detectores com o Convencional Single User: Aborda-se também o efeito do tamanho da janela de observação sobre o desempenho final em MUD assíncronos. Detectores Multiusuários mostram-se tolerantes aos desajustes de potência. combatem efetivamente a Interferência de Múltiplo Acesso (MAI), resultando em aumento de desempenho.
\end{abstract}

Palavras-chave: Sistemas DS-CDMA, detecção multiusuário subótima, eficiência assintótica multiusuário.

\begin{abstract}
This work makes a revision of the main suboptimum multiusers detectors (MUD) for DS-CDMA systems (Direct Sequence - Code Division Multiple Access). In this first part the fixed linear detectors are focused: Decorrelator and MMSE (Minimum Mean Square Error). It is explored the concepts of Asymptotic Multiuser Efficiency (AME) and the Near-Far Resistance (NFRes), being compared the performance of these detectors with Conventional Single-User. The effect of the size of the observation window is approached on the performance of asynchronous MUD. Multiuser Detectors are shown tolerant to the power unbalance and combat the Multiple Access Interference (MAI), resulting in performance increase.
\end{abstract}

Keywords: DS-CDMA systems, sub-optimum multiuser detection, asymptotic multiuser efficiency.

\section{INTRODUÇÃO}

Apesar das inúmeras vantagens do sistema de múltiplo acesso DS-CDMA Convencional (MF) ${ }^{1}$, tais como capacidade soft. facilidade de obtenção de soft handoler; rejeição de interferência de banda estreita e possibilidade de explorar combinações de diversidade de multipercurso no receptor, duas características desfavoráveis são inerentes a este sistema: o efeito near-far (NFR) e a MAI. A limitação

Taufik Abrão está com o Departamento de Engenharia Elétrica da Universidade Estadual de Londrina (UEL). Paul Jean E. Jeszensky está com o Departamento de Engenharia de Telecomunicações e Controle (PTC) e o Laboratório de Comunicações e Sinais (LCS) da EPUSP.E-mails: taufik@uel.br, pji@lcs.poli.usp.br

Editores Ad Hoc responsáveis: Max H. M. Costa e Dalton Soares Arantes. Artigo submetido em 06/2000 e aceito em 04/2001. de desempenho nestes sistemas é devida, principalmente, ao fato de múltiplos usuários dividirem a mesma faixa de frequiência. Esta interferência é resultado da impossibidade da manutenção da ortogonalidade entre todos os códigos de espalhamento recebidos, devido aos inevitáveis desajustes temporais aleatórios nos sinais dos usuários ativos. A MAI torna-se substancial quando o número de usuários cresce e/ou quando as potências não são perfeitamente controladas.

$O$ desempenho de um detector Convencional no combate à MAI depende fortemente de um conjunto de condições favoráveis:

1. seqüências de espalhamento com ótimas propriedades de correlação cruzada $\left(\rho_{i k}\right)$. Uma vez que quase todos os canais possuem algum grau de assincronismo, mesmo em sistemas síncronos, ou experimentam desvanecimento multipercurso, impossibilitando a exploração da eventual ortogonalidade entre as sequiências de espalhamento, buscam-se famílias de códigos com baixas correlações cruzadas [1], tais como as seqüências de fase preferencial [2] e as de Hadamard-Sylvester [3]. Este problema é acentuado ainda mais pelo efeito nearfar. Este efeito ocorre principalmente no enlace reverso (móvel, MS, para estação radio base, BS) quando sinais fracos de estações móveis distantes são "sufocados" por sinais fortes provenientes de estações móveis, próximas à BS. Mesmo quando as MS estão à mesma distância da BS, o canal pode introduzir desvanecimento, resultando no mesmo efeito near-far.

2. Assim, deve-se obter acurácia nos procedimentos de controle de potência, onde a BS ajusta o nível de potência das estações móveis, de tal sorte que no receptor da BS todos os sinais cheguem com a mesma intensidade, combatendo o efeito near-far ${ }^{2}$.

3. códigos corretores de erro permitem obter desempenhos aceitáveis em termos de taxa de erro de bit (BER) para baixos níveis de SNR. Códigos convolucionais e FEC são exemplos.

4. antenas adaptativas/setorizadas: nas antenas adaptativas, as direções são ajustadas dinamicamente, utilizando-se de processamento de sinais adaptativos para focalizar a antena em uma determinada direção correspondente ao usuário de interesse.

${ }^{1}$ (Matched Filter) Filtro casado à seqüencia de espalhamento do usuário de interesse e detecção considerando informações de um único usuário.

20 Padrão IS-95 implementa um laço aberto con potências transmitidas pelos móveis inversamente proporcionais às potências recebidas, e laço fechado. onde a BS envia comandos para controlar a potencia transmitida em cada móvel. Garante-se assin que todos os sinais recebidos na BS difiram entre si de no máximo $1 d B$ 
Caso a MAI seja mantida em limites razoáveis, através de um projeto do conjunto de sequiências de espalhamento que resulte em baixos valores de correlações cruzadas e o sistema se mantiver pouco carregado, limitando o número máximo de usuários ativos em cerca de $10 \%$ a $20 \%$ do ganho de processamento, então é possível empregar a técnica convencional de filtros casados na detecção dos sinais com uma perda de desempenho aceitável. Por outro lado, quando o sistema apresentar requisitos de carregamento intenso. como no caso de sistemas de $3^{a}$ geração e auviuinüunientie o controle de potência não for perfeito, então a perda de desempenho será substancial e intolerável. Estas são as principais razões

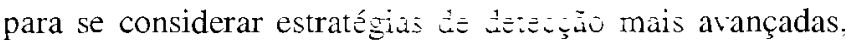
tais como MUD

O detector Convencional segue a estratégia de detecção única (single user); cada ramo do receptor da BS (canal reverso) detecta apenas um único usuário sem levar em consideração a existência dos demais. Não há compartiIhamento da informação ou processamento conjunto de sinais. Já na detecção multiusuário, informações de todos os usuários são utilizadas em conjunto para melhorar a detecção de cada usuário individualmente. Assim, enquanto a detecção single-user não leva em conta a interferência causada pelos demais usuários, na detecção MUD as informações de código, de atraso, amplitude e fase de todos os usuários ativos são utilizadas a fim de melhor detectar cada usuário de interesse.

Projetos de MUD surgem para aliviar o problema da limitação de desempenho e capacidade de sistemas DS-CDMA convencionais. Em [4], [5], [6], [7], Verdú e Lupas determinaram o ganho de desempenho e capacidade de MUD ótimo e subótimos (lineares) síncronos e assíncronos em relação ao sistema Convencional, minimizando a necessidade de controle de potência.

O detector multiusuário Ótimo [4] consiste em um banco de filtros casados seguido de um detector de seqüência de máxima verossimilhança, MLSE (Maximum Likelihood Sequence Estimation or Detection). O detector MLSE produz a seqüência de máxima verossimilhança, $\widehat{b}$, em relação à sequiência transmitida. Estima-se o vetor $\mathbf{b}$ de forma a maximizar a probabilidade conjunta a posteriori ${ }^{3}$. Existe um problema na implementação do detector MLSE: como são possíveis $2^{\mathcal{M K}}$ vetores para $\mathbf{b}$ ( $K=$ número de usuários ativos no sistema; $\mathcal{M}=$ tamanho da mensagem), uma busca exaustiva torna-se impraticável. No entanto, em [4] foi mostrado que o critério MLSE pode ser implementado para DSCDMA a partir de filtros casados seguido por algoritmo de Viterbi, embora existam desvantagens: a) ainda resulta $\mathrm{em}$ complexidade exponencial em relação a $\mathrm{K}$. da ordem de $2^{K}$; b) requer o conhecimento das amplitudes e fases recebidas, e como estes parâmetros não são conhecidos a priori, necessitam ser estimados; c) sistemas DS-CDMA reais possuem um grande número de usuários, resultando em custo de implementação ainda elevado.

Dada a proibitiva complexidade computacional inerente ao

${ }^{3} P(b \mid r(t), \forall t)$ : isto é a probabilidade da sequiência de dados ter sido transmitida dado que $r(t)$ foi recebido. onde $r(t)$ estende-se por toda a mensagem. Assume-se a hipótese de todas as mensagens transmitidas serem equiprováveis. detector Ótimo, inúmeras propostas para a implementação de MUD subótimos (lineares e subtrativos), com complexidade linear com o número de usuários, foram feitas na última década. Una possível esquematização para os vários tipos de detectores multisuários pode ser vista na figura 1. Classificações para MUD incluem [8], [9], [10]

- versões fixas e adaptativas, conforme os coeficientes do filtro que processa o sinal de entrada sejam invariantes no tempo ou mudem de forma que o receptor se adapte às nuudanças do canal:

- lineares e não-lineares, quando o sinal multiusuário recebido passa por uma transformação linear, desacoplando os sinais interferentes do sinal de interesse, ou empregue o princípio subtrativo para obter o cancelamento de interferência a partir da detecção e reconstrução dos sinais interferentes.



Figura 1. Classificação geral para detectores multiusuários lineares e subtrativos.

Dentre os MUD lineares fixos largamente estudados na literatura tem-se: o Descorrelacionador e o de Erro Mínimo Quadrático Médio (MMSE). Ambos resultam em substancial aumento de desempenho e capacidade em relação ao detector Convencional. A idéia básica em detecção subótima linear consiste na aplicação de uma transformação linear à saída do banco de filtros casados a fim de reduzir a MAI, vista a partir de cada usuário. O receptor linear Descorrelacionador remove todas as correlações cruzadas entre os usuários empregando uma transformação correspondente à inversa da matriz de correlação das sequiências de espalhamento dos usuários ativos, enquanto que o MMSE aplica uma transformação visando a redução do erro quadrático médio (MSE, Mean Square Error) à saída do receptor, aliviando o problema do aumento de ruído presente à saída do Descorrelacionador. O detector MMSE resulta em igual ou melhor desempenho que o Descorrelacionador: porém, requer estimação das potências recebidas.

Além dos subótimos lineares, existem os MUD subótimos Subtrativos (não lineares), cujo princípio de operação consiste na geração de estimativas para a MAI e posteriormente no cancelamento destas parcelas do sinal recebido, gerando versões para o sinal a ser detectado parcialmente livres de 
MAI. Fazem parte dessa estratégia as estruturas baseadas no cancelamento de interferência sucessivo, SIC (Sucessive Interference Cancellation) e paralelo, PIC (Parallel Interference Cancellation) ${ }^{4}$, além do detector de decisão realimentada ZF-DF (Zero Forcing Decision Feedback).

Existem ainda versões adaptativas para a técnica de detecção multiusuário subótima. Três formas de implementação desses algoritmos foram propostas: versões adaptativas para o Descorrelacionador [11], MMSE Adaptativo [12], [13] e Cancelamento de Interferência Adaptativo [14]. A segunda parte deste trabalho [15] é dedicada aos MUD do tipo cancelamento de interferência subtrativos.

As principais vantagens associadas aos MUD são:

1. significativo aumento de capacidade: o limite pode ser aumentado ainda mais através da inclusão de sinais, provenientes de células vizinhas, no algoritmo de detecção multiusuário. Embora a detecção multiusuário ainda não seja factível para o canal direto, em DS-CDMA, a limitação ocorre no canal reverso.

2. utilização mais eficiente do espectro no canal reverso: aumento de desempenho no canal reverso permite que os móveis operem com ganhos de processamento mais baixos, conduzindo a uma menor BW. A BW extra poderá ser empregada no aumento de capacidade do canal direto.

3. requisito de controle de potência reduzido: em ambiente multiusuário, uma vez reduzido o impacto da MAl, relaxa-se a exigência da igualdade das energias recebidas.

4. eficiência de potência: a redução da interferência no canal reverso pode resultar em redução no requisito de potência transmitida pelos móveis.

Como limitações, pode-se apontar duas:

1. MAI das células vizinhas: caso a interferência intercelular não seja incluída no algoritmo de detecção, o potencial ganho é reduzido. Para sistema sem detecção multiusuário, desprezando-se o ruído Gaussiano aditivo branco (AWGN), a interferência total no sistema será:

$$
I=I_{M A I}+f . I_{M A I}
$$

com $I_{M A I}=$ interferência intracelular e $f=$ razão de MAI intercelular para intracelular. Considerando sistema MUD ideal, toda MAI intracelular é eliminada, restando ainda a parcela ${ }^{5} f . I_{M A I}$. E como a MAI é proporcional ao número de usuários, $\circ$ fator de ganho de capacidade máximo em relaçâo ao sistema convencional será $G_{\max }=\frac{(1+f)}{f}$. Valor típico para $f=0.55$ [16], resultando em $G_{\max } \approx 2.8$.

2. Dificuldade de implementação do MUD no canal direto: por questões de custo, compactação, consumo de

\footnotetext{
${ }^{4}$ Existem versões híbridas combinando-se o cancelamento paralelo e sucessivo em grupos de usuários (Groupwise). G-PIC e G-SIC

${ }^{5}$ Podendo ser tratada en alguns algoritmos MUD mais complexos (por exemplo, MMSE adaptativos). ou simplesmente ser tratada cono AWGN. como ocorre freqüentemente.
}

potência etc, ainda não é razoável a implementação no receptor do móvel; além do que haverá problemas de privacidade caso os códigos de espalhamento dos usuários interferentes sejam conhecidos no receptor do móvel. Está sendo considerada a implantação do MUD apenas na BS em sistemas celulares de terceira geração (3G). Porém, o aumento de capacidade deve ser obtido tanto no canal direto quanto no reverso, visando um efetivo aumento de capacidade. No entanto, esta limitação está se tornando cada vez menor com os crescentes avanços em DSP e FPGA ${ }^{6}$, obtendo-se sistemas/circuitos com níveis de funcionalidade e velocidade crescentes e consumos de potência reduzidos.

Para operarem adequadamente, as diversas estruturas multiusuário necessitam conhecer os diversos parâmetros de sistema, relacionados ao usuário de interesse e aos interferentes. A tabela 1 apresenta requisitos para os principais detectores multiusuários e Convencional (MF), em termos de sequiências de espalhamento, amplitudes e atrasos dos usuários ativos; compara o esforço computacional necessário à implementação dos algoritmos, em função da complexidade temporal assintótica por decisão de bit, TBC. Este parâmetro corresponde ao número de operações requeridas para que o algoritmo de decisão estime a sequiência de dados transmitida dividido pelo número total de bits demodulados, quando o número de bits transmitidos for muito grande $(\mathcal{M} \rightarrow \infty)$ [4], [17]. A TBC de $p\left(K^{*}\right)$ será denotada por $\mathcal{O}\left(f\left(K^{r}\right)\right)$ quando, para $K^{-}$suficientemente grande, existir uma constante $c$ tal que $f(K) \leq c . p(K)$. Para uma análise mais criteriosa da complexidade computacional dos diversos receptores multiusuário, veja [18], [19].

\begin{tabular}{|c|c|c|c|c|c|c|c|}
\hline Ręulusitio & $\begin{array}{l}\text { Cont. } \\
\text { (MF) }\end{array}$ & $\begin{array}{l}\text { Otimo } \\
\text { (MLSE, }\end{array}$ & $\begin{array}{l}\text { Descor- } \\
\text { relacion. }\end{array}$ & $\begin{array}{l}\text { MMSE } \\
\text { Linear }\end{array}$ & $\begin{array}{l}\text { PIC e } \\
\text { SIC }\end{array}$ & 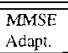 & $\begin{array}{l}\text { MMSE } \\
\text { Cego }\end{array}$ \\
\hline$\overline{\text { Sell. Us. Desejade }}$ & 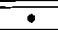 & 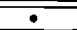 & - & - & 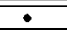 & & $\div$ \\
\hline Seq. Interferentue & & - & - & - & . $b$ & & \\
\hline Alraso Us. Desejado & $\cdot$ & $\bullet$ & $\bullet$ & $\div$ & $\bullet$ &. & $\cdot$ \\
\hline Atraso Interferentes & &  & $\cdot$ & $\cdot$ & - & & \\
\hline Amplit. Recebidas & it & $\bullet$ & & $\cdot$ & $\cdot$ & & \\
\hline Nivel de Rlido & & & & $\div$ & & & \\
\hline Seq. Trellamento & & & & & & $\cdot$ & \\
\hline Complendide [TBC] & $\begin{array}{l}\text { indep. } \\
\text { Je K }\end{array}$ & $\operatorname{or} \frac{2 \mathrm{~K}}{\overline{\mathrm{K}}}$ & $\mathrm{O}\left(\mathrm{K}^{3}\right)$ & $O\left(K^{-3}\right)$ & $O \mathrm{~K}^{ل}$ & $S_{\left(\mathrm{K}^{3}\right)}$ & $<_{\left(\mathrm{K}^{3}\right)}$ \\
\hline  & 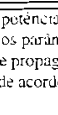 & npoten & $\begin{array}{l}\text { eleme } \\
\text { es fon } \\
\text { bolo } \\
\text { cebidi }\end{array}$ & תie. & & & \\
\hline
\end{tabular}

Tabela 1. Requisitos para os principais MUD e o Convencional

Note que os detectores baseados no cancelamento de interferência subtrativos são atrativos devido a sua baixíssima complexidade de implementação, embora requeiram acurácia nas estimações de parâmetros de canal. Já o detector Ótimo multiusuário é utilizado como referência na comparação de desempenho de detectores MUD sub-ótimos, apesar de resultar em complexidade computacional exponencial com o número de usuários, inviabilizando sua implementação. Finalmente, as técricas adaptativas de detecção multiusuário requerem conhecimento de um conjunto mínimo de parâmetros, porém apresentam redução na eficiência espectral devido à necessidade de treinamento do

\footnotetext{
${ }^{5}$ Processamento Digital de Sinais (Digital Signal Processing) e Arranjo Lógico Programável pelo Usuário (Fieia Programmable Gate Array), respectivamente.
} 
canal e problemas de convergência (receptores Adaptativos Cegos).

\section{MODELO DE SISTEMA}

Para a descrição do sistema DS-CDMA empregar-se-á um modelo de sinais em banda base equivalente. Assume-se canal estacionário e filtragem casada ao nível de chip. A figura 2.a apresenta uma forma equivalente para um conjunto de transmissores assíncronos DS-CDMA em canal estacionário. O vetor amostra à saída do filtro casado, empregado na detecção do i-ésimo símbolo transmitido, pode ser descrito por [12]:

$$
\mathbf{r}[i]=\sum_{j=1}^{J} A_{j} b_{j}[i] \mathbf{p}_{j}+\mathbf{n}[i],
$$

onde $b_{j} \in\{1 .-1\}$ é o conjunto de bits de dados transmitidos, assumidos equiprováveis, independentes e de duração igual a $T ; E_{j}=A_{j}^{2}=$ energia recebida correspondente ao símbolo $b_{j} ;\left\{\mathbf{p}_{j}\right\}=$ conjunto de vetores com energia unitária. formado pela combinação dos efeitos de espalhamento e distorção em um modelo de canal mais geral; $J=$ número de retores de sinais, interferentes e de interesse, que compõem o sinal recebido no intervalo. Para S-CDMA, $J=h^{\circ}$ : para $\therefore$-CDMA,$J>K$ e para canal AWGN, $J \leq 2 K-1$; $\mathbf{r}[\hat{i}] \in \mathbb{R}^{N}$, é o conjunto de todos vetores amostra de dimensão $N$ definido no campo dos números reais: $N=$ comprimento do filtro do receptor e, em muitos casos, igual ao ganho de processamento; $\mathbf{n}[i]=$ amostras de ruído, dimensão V.

Assume-se modulação BPSK devido a simplificação na ználise. Note que o tempo de observação é finito, apesar do detector ótimo requerer um intervalo de observação infinito. Este modelo em banda base em geral é suficiente para permitir a análise de sistemas DS-CDMA síncronos e assíncronos em canais invariantes no tempo. Efeitos de distorção de canal, formatação de pulso, instante de amostragem e rotação de fase podem ser incluídos na definição dos vetores $\mathbf{p}_{j}$.

\subsection{DS-CDMA SÍNCRONO (S-CDMA) EM CA- NAL AWGN}

Para um sistema síncrono em um canal com AWGN e filtro do receptor casado para exatamente $\mathcal{M}=1$ símbolo, $\mathbf{p}_{j}$ representa o código de espalhamento recebido em banda base zmostrado e $J=K$, o número de usuários ativos no sistema. Para recepção coerente em canal com $A W G N$, vale

$$
\mathbf{p}_{j}=\mathbf{s}_{j},
$$

onde $\mathrm{s}_{j}$ é o vetor seqüência de espalhamento normalizada. isto é $\left\|\mathbf{s}_{j}\right\|^{2}=\int_{0}^{T} s_{j}^{2}(t) d t=1$, empregado na transmissão do símbolo $b_{j}$, definido por:

$$
\mathbf{s}_{k}(t)=\sum_{i=0}^{N-1} \mathbf{c}_{k}^{(i)} p_{T_{0}}\left(t-i I_{c}\right)
$$

com $c_{k}^{(i)}=$ vetor de chips, com elementos $c_{k}^{(i)} \in\{ \pm 1\}$ de duração $T_{c}$, empregado no intervalo de chip definido por $i$ : e

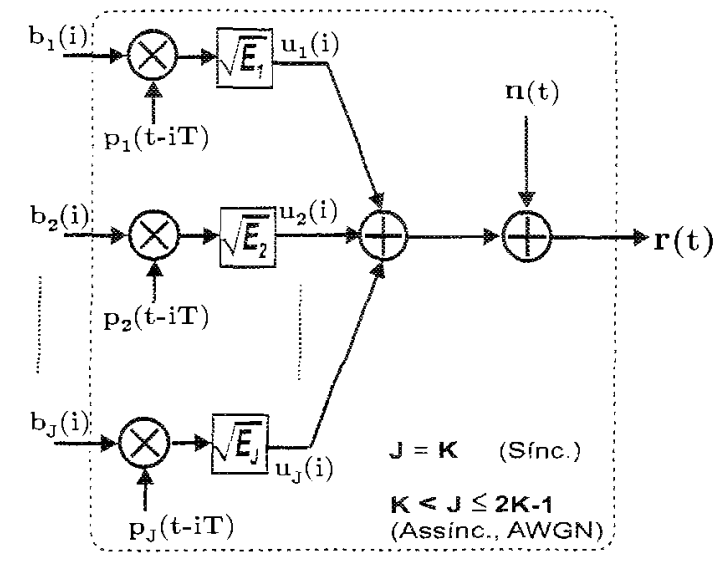

(a) Transmissor + Canal

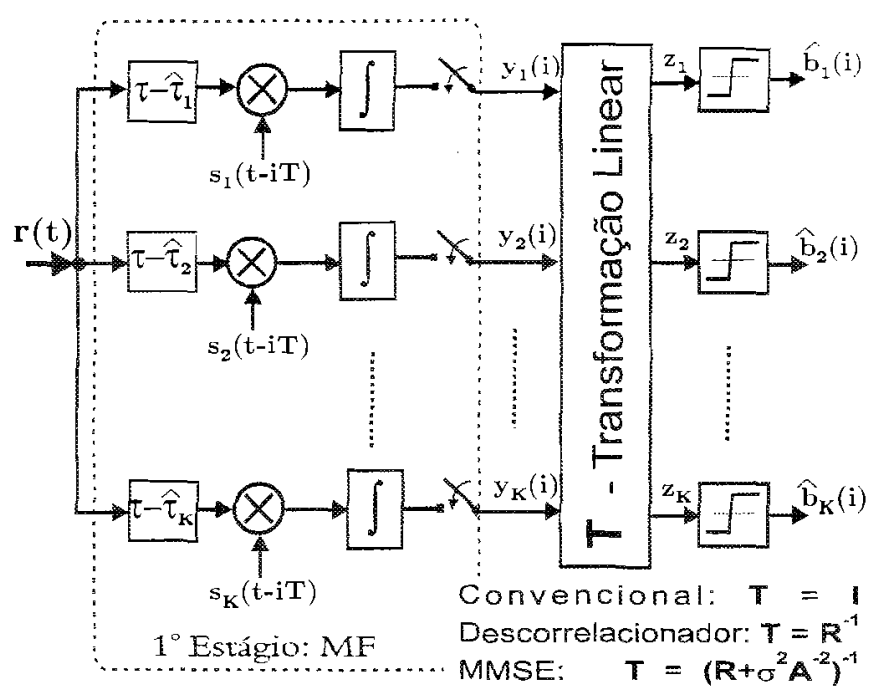

(b) Receptor

Figura 2. Representação genérica em banda base equivalente discreto para um sistema DS-CDMA com símbolos $\left\{b_{j}\right\}$ espalhados pelos vetores $\left\{\mathbf{p}_{j}\right\}$. (a) Transmissor + Canal; (b) Receptor. Para sistemas S-CDMA, todos os atrasos $\tau_{k}$ são conhecidos exatamente.

$p_{T_{0}}()=$. pulso retangular de amplitude unitária no intervalo $\left[0 . T_{c}\right)$.

Definem-se a matriz espalhamento,

$$
\mathbf{P}=\left[\mathbf{p}_{1} \mathbf{p}_{2} \ldots \mathbf{p}_{K}\right]
$$

as matrizes diagonais energia e amplitude,

$$
\begin{aligned}
& \mathbf{E}=\operatorname{diag}\left(E_{1}, E_{2}, \ldots, E_{K^{*}}\right), \\
& \mathbf{A}=\operatorname{diag}\left(\sqrt{E_{1}}, \sqrt{E_{2}}, \ldots, \sqrt{E_{K}}\right),
\end{aligned}
$$

e o vetor de símbolos transmitidos durante o intervalo de interesse,

$$
\mathbf{b}=\left(b_{1}, b_{2} \ldots . b_{K}\right)^{\top}
$$

Empregando-se a notação vetorial, o vetor sinal recebido pode ser reescrito como

$$
\mathbf{r}=\mathbf{P} \sqrt{\mathbf{E}} \mathbf{b}+\mathbf{n},
$$

onde $\mathbf{n}$ é um vetor ruído Gaussiano com densidade espectral de potência bilateral igual $N_{0} / 2$. Para uma introdução à 
notação adotada nesta seção e subsequientes, vide [17] em seu item 2.9.

Em um receptor Convencional, a saída do banco de filtros casados sincronizados, figura 2.b (com transformação linear $\mathbf{T}=\mathbf{I}_{N} \cdot \operatorname{com} \mathbf{I}_{N}=$ matriz identidade, dimensão $N \times N$ ), é um vetor com $I^{\prime}$ componentes dado por:

$$
\mathbf{y}=\mathbf{P}^{H} \mathbf{r}=\mathbf{R} \sqrt{\mathbf{E}} \mathbf{b}+\widetilde{\mathbf{n}},
$$

onde $\widetilde{\mathbf{n}}=\mathbf{P}^{H} \mathbf{n}$ é o vetor amostra do ruído colorido; $(\cdot)^{H}=$ operador hermitiano transposto: $(\mathbf{A})^{H}=\left(\mathbf{A}^{*}\right)^{\top}$. A matride correlação (auto e cruzada) normalizada é definida por

$$
\mathbf{R}=\mathbf{P}^{H} \mathbf{P}=\left\{\rho_{j k}\right\},
$$

$\operatorname{com} \rho_{j k}=\left\langle\mathbf{p}_{j} \cdot \mathbf{p}_{k}\right\rangle=\int_{0}^{T} p_{j}^{H}(t) \cdot p_{k}(t) d t$. elemento de conrelação cruzada entre os vetores de espalhamento normalizados do j-ésimo e k-ésimo usuário.

A matriz das correlações desnormali-ada, cujo elemento $(j, k)$ é obtido pelo produto $\left\langle A_{j} \mathrm{p}_{j}, A_{k} \mathrm{p}_{k}\right\rangle$, será denotada por

$$
\mathbf{H}=\sqrt{\mathbf{E R}} \sqrt{\mathbf{E}}=\mathbf{A R A} .
$$

O detector Convencional toma as decisões baseado na polaridade dos sinais à saída do integrador, $\mathbf{y}$, obtendo-se o vetor informação estimada

$$
\hat{\mathbf{b}}=\operatorname{sgn}(\mathbf{y}) \text {. }
$$

Caso o receptor seja projetado para operar $\operatorname{com} \mathcal{M}$ símbolos, o número de bits que afeta o sinal recebido em qualquer instante dado será $J=\mathcal{M} K^{\circ}$. Assim, para $\mathcal{M}=$ 3 , a matriz dos vetores de dados espalhados será, no caso síncrono,

$$
\mathbf{P}=\left[\begin{array}{cccccccccc}
s_{1} & s_{2} & \cdots & s_{K} & 0 & \cdots & 0 & 0 & \cdots & 0 \\
0 & 0 & \cdots & 0 & s_{1} & \cdots & s_{K} & 0 & \cdots & 0 \\
0 & 0 & \cdots & 0 & 0 & \cdots & 0 & s_{1} & \cdots & s_{K}
\end{array}\right]
$$

com a matriz energia dada por

$$
\mathrm{E}=\operatorname{diag}\left(E_{1}, E_{2}, \ldots . E_{K} \cdot E_{1}, E_{2}, \ldots . E_{K^{-}} \cdot E_{1} . E_{2} \ldots, E_{K}\right) .
$$

E neste caso, o vetor de símbolos transmitidos será

$$
\begin{array}{r}
\mathbf{b}=\left(b_{1,-1}, b_{2 .-1}, \ldots, b_{K,-1}, b_{1.0}, b_{2.0}, \ldots .\right. \\
\left.b_{K, 0} \cdot b_{1,1}, b_{2.1} \ldots, b_{K, 1}\right)^{\top},
\end{array}
$$

$\operatorname{com} b_{k, i}=i$-ésimo bit (offset temporal, múltiplo do período de bit, $T_{b}$ ) do $k$-ésimo usuário; $0=$ vetor zero de mesma dimensão de $\mathrm{s}_{k}$.

\subsection{DS-CDMA ASSÍNCRONO (A-CDMA) EM CANAL AWGN}

Em sistemas A-CDMA, cada usuário interfere em múltiplos bits consecutivos; portanto, ter-se-á $J>I$ na representação genérica discreta equivalente da figura 2.a. Em um canal AWGN, $J \leq 2 \hbar-1$ caso o filtro do receptor seja escolhido para processar um símbolo por vez, $M=1$ ( janela de observação $=1 T$ ). admitindo-se adicionalmente a obtenção de perfeito sincronismo com o símbolo do usuário de interesse. Nestas condições, a matriz $\mathbf{P}$ resultante é similar à matriz em (14), exceto que agora não terá uma estrutura regular. Por exemplo, para o caso de um sistema com dois usuários, janela de observação $\mathcal{M}=1$. ganho de processamento igual a 7 e atraso do segundo usuário igual a 4 períodos de chip, $\tau_{2}=4 T_{c}$, relativo ao primeiro, como definido na figura 3.a, resultam em 3 usuários virtuais, com matriz de espalhamento

$$
\mathbf{P}=\left[\begin{array}{ccccccc}
s_{11} & s_{12} & s_{13} & s_{14} & s_{15} & s_{16} & s_{17} \\
s_{25} & s_{26} & s_{27} & 0 & 0 & 0 & 0 \\
0 & 0 & 0 & s_{21} & s_{22} & s_{23} & s_{24}
\end{array}\right]^{\top}
$$

$s_{k, j}=$ elementos da sequiência de espalhamento para o usuário $k$, após normalização a fim de garantir que os $\mathrm{p}_{k}$ sejam vetores com energia unitária.
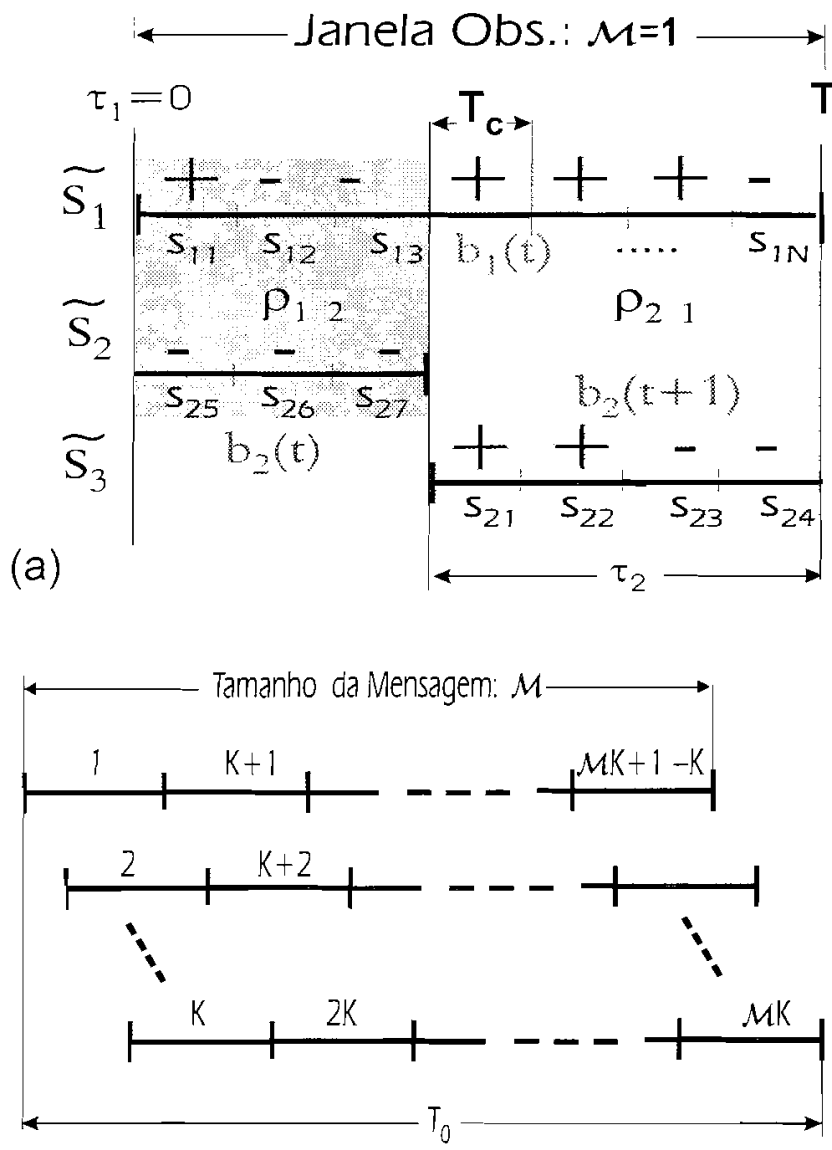

(b)

Figura 3. Correlações e Atrasos para sistemas A-CDMA: (a) Correlações para 2 usuários assíncronos com sequiências de Gold 7 equivalendo a 3 usuários síncronos virtuais; janela de observação $\mathcal{M}=1 T$ (b) Mensagem transmitida por $\mathrm{K}$ usuários assíncronos com atrasos ordenados.

Genericamente, considera-se atrasos relativos entre usuários $\tau_{1} . \tau_{2} \ldots \ldots \tau_{h}$ com $\tau_{k} \geq 0$, onde $\tau_{k}$ pode ser escrito como a soma de um número inteiro de períodos de chip, $T_{c}$, e uma fração de sub-chip, $\delta_{k}$,

$$
\tau_{k}=\left(t_{k}+\delta_{k}\right) T_{c}
$$

$\operatorname{com} t_{k}=\left\lfloor\frac{\tau_{k}}{T_{c}}\right\rfloor$, parte inteira da divisão. Admitindo-se inicialmente que todos os atrasos sejam múltiplos inteiros do 
período de chip, $\delta_{k}=0 . \forall \hbar$. a matriz de espalhamento terá dimensão $N \times 2 K$, para $\mathcal{M}=1$, sendo definida por:

$$
\begin{aligned}
& \mathbf{P}=\left[\mathbf{p}_{1} \mathbf{p}_{2} \ldots \mathbf{p}_{2 K}\right]=
\end{aligned}
$$



As representações obtidas anteriormente para o sinal recebido e a saída do filtro casado, (2), (9) e (10), ainda são válidas para A-CDMA, com as devidas redefiniçōes de P.E e b. Admitindo-se atrasos ordenados, $\tau_{k} \geq 0$ e $M=1$, o vetor sinal recebido será:

$$
\mathbf{r}(t)=\mathbf{P} \sqrt{\mathbf{E}}\left[\begin{array}{c}
\mathbf{b}(t) \\
----- \\
\mathbf{b}(t+T)
\end{array}\right]+\mathbf{n}(t)
$$

com vetor coluna $\mathrm{b}$ de dimensão $2 K$ e a matriz diagonal $\mathrm{E}$. dimensão $2 K \times 2 K$, resultando em um sistema equivalente síncrono com o dobro de usuários.

O modelo em tempo discreto para o vetor saída do banco de filtros casados para um canal assíncrono será

$$
\begin{aligned}
\mathbf{y}[i]=\mathbf{R}^{H}[1] \sqrt{\mathbf{E}} \mathbf{b}[i-1]+\mathbf{R}[0] \sqrt{\mathbf{E}} \mathbf{b}[i]+ \\
+\mathbf{R}[1] \sqrt{\mathbf{E}} \mathbf{b}[i+1]+\mathbf{n}[i],
\end{aligned}
$$

onde as matrizes de correlação devido ao assincronismo dos usuários, $\mathbf{R}[0]$, $\mathbf{R}[1]$, são definidas pelos elementos

$R_{j k}[0]=\left\{\begin{array}{ll}1 & \text { se } j=k \\ \rho_{j k} & \text { se } j<k \\ \rho_{k j} & \text { se } j>k\end{array} \quad\right.$ e $\quad R_{j k}[1]= \begin{cases}0 & \text { se } j \geq k \\ \rho_{k j} & \text { se } j<k\end{cases}$ cujos elementos de correlação cruzada par e ímpar são dadas por

$$
\begin{aligned}
\rho_{i j} & =\int_{\tau}^{T} s_{i}^{H}(t) s_{j}(t-\tau) d t, \\
\rho_{j i} & =\int_{0}^{\tau} s_{i}^{H}(t) s_{j}(t+T-\tau) d t,
\end{aligned}
$$

com $\tau=\tau_{j}-\tau_{i} \geq 0$, atraso relativo entre as duas seqüências de espalhamento. Uma vez que os sinais são nulos fora do intervalo $[0, \mathrm{~T}]$,

$$
\begin{aligned}
\mathbf{R}[m] & =0 \quad \forall|m|>1, \\
\mathbf{R}[-m] & =\mathbf{R}^{H}[m] .
\end{aligned}
$$

A forma matricial de (21), para o caso de 2 usuários com atrasos ordenados $\tau_{1} \leq \tau_{2}$. figura 3.a, é representado em termos de bits de dados $b_{1}$ e $b_{2}$ por:

$$
\begin{aligned}
& {\left[\begin{array}{l}
y_{1}(i) \\
y_{2}(i)
\end{array}\right]=\underbrace{\left[\begin{array}{cc}
0 & 0 \\
\rho_{21} & 0
\end{array}\right]}_{\mathbf{R}[-1\}=\mathbf{R}^{H}\{1]} \cdot\left[\begin{array}{l}
b_{1}(i-1) \\
b_{2}(i-1)
\end{array}\right]+\underbrace{\left[\begin{array}{cc}
1 & \rho_{12} \\
\rho_{12} & 1
\end{array}\right]}_{\mathbf{R}[0]} .} \\
& {\left[\begin{array}{l}
b_{1}(i) \\
b_{2}(i)
\end{array}\right]+\underbrace{\left[\begin{array}{cc}
0 & \rho_{21} \\
0 & 0
\end{array}\right]}_{\mathbf{R}[1]} \cdot\left[\begin{array}{l}
b_{1}(i+1) \\
b_{2}(i+1)
\end{array}\right]+\left[\begin{array}{l}
n_{1}(i) \\
n_{2}(i)
\end{array}\right] .}
\end{aligned}
$$

A fim de tornar a notação mais compacta, define-se a matri- de correlação Hermitiana ${ }^{7}$ e Toeplit ${ }^{-8}$ por blocos, dimensão $\mathcal{M} \mathrm{H}^{-} \times \mathcal{M}$

$$
\mathfrak{R}=\left[\begin{array}{ccccc}
\mathbf{R}(0) & \mathbf{R}(1)^{H} & 0 & \cdots & 0 \\
\mathbf{R}(1) & \mathbf{R}(0) & \mathbf{R}(1)^{H} & & \vdots \\
0 & \mathbf{R}(1) & \mathbf{R}(0) & \ddots & 0 \\
\vdots & & \ddots & \ddots & \mathbf{R}(1)^{H} \\
0 & \ldots & 0 & \mathbf{R}(1) & \mathbf{R}(0)
\end{array}\right]
$$

Com esta notação, a forma matricial para a saída do banco de filtros casados em um sistema assíncrono com tamanho da mensagem finito, $\mathcal{M}$. torna-se

$$
\mathrm{y}=\mathfrak{R A b}+\widetilde{\mathbf{n}},
$$

onde $\mathfrak{R}$ é reinterpretada como a matriz de correlação para um sistema equivalente síncrono cuja mensagem inteira transmitida é processada pelo receptor, resultando em $\mathcal{M} K$ usuários virtuais, figura 3.b.

Note-se que em sistemas assíncronos práticos, os usuários interferentes são recebidos com atrasos relativos nem sempre múltiplos inteiros do sinal do usuário de interesse (figura 3.a). Assim, o atraso relativo real para o $\mathrm{k}$-ésimo usuário interferente, $\tau_{k}$. será dado por (18) com a fração de sub-chip, $\delta_{k} \neq 0$.

Define-se ainda sistemas CDMA Quase Síncronos (QSCDMA) quando os atrasos para todos os usuários estiverem confinados a um intervalo muito menor que o período de símbolo, tipicamente menores que $3 T_{c}$.

Assumindo-se formatação de pulso retangular e integração do sinal em banda base a cada intervalo de símbolo, o efeito do sub-chip $\delta_{k}$ no cálculo da matriz de correlação é a combinação linear dos valores dos chips adjacentes na proporção de $\delta_{k}$. No modelo A-CDMA adotado aqui não há a exigência da coerência para as portadoras, uma vez que a influência da fase de cada portadora, $\Theta_{k}$, sobre a detecção poderá será absorvida adicionado-se a $\delta_{k}$ o atraso corresponde a $\phi_{k}$.

\section{MEDIDAS DE DESEMIPENHO}

Objetivando a comparação dos vários receptores CDMA e evitar o cálculo muitas vezes complexo da taxa de erro de bit, definem-se duas medidas de desempenho assintóticas: a AME e a NFRes.

\footnotetext{
${ }^{7}$ Uma matriz de valores complexos é Hermitiana se for igual à sua matriz conjugada transposta.

${ }^{8}$ Uma matriz será Toeplitz se todos os elementos de sua diagonal principal são iguais e se os elementos de qualquer outra diagonal paralela à princi-
} pal também forem iguais. 


\subsection{EFICIÊNCIA ASSINTÓTICA MULTI- USUÁRIO, AME}

É uma medida da influência que os usuários interferentes exercem sobre a taxa de erro de bit do usuário de interesse. Para se obter a eficiência assintótica, deve-se relacionar a probabilidade de erro multiusuário com a probabilidade de erro de um sistema Convencional. $\mathrm{Na}$ ausência de usuários interferentes, a relação sinal-ruído (SNR) à saída do k-ésimo filtro casado é $\left(\frac{A_{k}}{\sigma}\right)^{2}$; na presença de interferentes síncronos torna-se:

$$
\left(\frac{A_{k}}{\sigma}\right)_{\text {Conk }}^{2} \triangleq \frac{A_{k}^{2}}{\sigma^{2}+\sum_{j \neq k}\left(A_{j} \rho_{j k}\right)^{2}}
$$

A presença de outros usuários no canal contribui para aumentar a BER. Visando quantificar a probabilidade de erro multiusuário, define-se energia efetiva do usuário $k$, $e_{k}(\sigma)$, como a energia que este usuário requer para obter idêntica probabilidade de erro de bit em um canal AWGN com um único usuário (single-user, ausência de interferentes) e mesmo nível de ruído de fundo, dada pela função densidade de probabilidade Gaussiana ${ }^{9}$

$$
P_{k}=Q\left(\frac{\sqrt{\mathrm{e}_{k}(\sigma)}}{\sigma}\right)
$$

A eficiência multiusuário (ME) para o k-ésimo usuário é dada pela razão da sua energia efetiva pela energia real requerida por este usuário em um sistema multiusuário. considerando o mesmo desempenho de BER

$$
\eta_{k}(\sigma) \triangleq \frac{\mathrm{e}_{k}(\sigma)}{A_{k}^{2}}=\frac{S N R_{\mathrm{efet}}(\text { s.u. })}{S N R_{\text {real }}(\text { m.u. })_{\text {ausência Interf. }}}
$$

A eficiência multiusuário quantifica a perda de desempenho devido à existência de outros usuários no canal, sendo função das sequiências de espalhamento, das relações SNRs e do tipo de detector empregado. Finalmente, a eficiência assintótica multiusuário encontra definição na região de alta relação Sinal-Ruído como o limite [5]:

$$
\eta_{k} \triangleq \lim _{\sigma \rightarrow 0} \frac{e_{k}(\sigma)}{A_{k}^{2}}
$$

e mede a inclinação $r$ com que a probabilidade de erro de bit para o $k$-ésimo usuário, $P_{k}$. vai a 0 (escala logarítmica) na região de alta relação sinal ruído:

$$
\begin{aligned}
\eta_{k} & =\sup \left\{0 \leq r \leq 1: \lim _{\sigma-0} \frac{P_{k}(\sigma)}{Q\left(\sqrt{r} \frac{A_{k}}{\sigma}\right)}=1\right\} \\
& =\frac{2}{A_{k}^{2}} \lim _{\sigma \rightarrow 0}\left[\sigma^{2} \log \frac{1}{P_{k}(\sigma)}\right]
\end{aligned}
$$

isto é, a taxa de erro de bit logarítnica do k-ésimo usuário deve ir a zero com a mesma inclinação que a do single user com energia $\eta_{k} A_{k}^{2}$. uma vez que na ausência de outros

\footnotetext{
${ }^{9}$ Função $Q$ (relacionada à função erro complementar) de uma variável aleatória $x$ de média zero e variância normalizada. $Q(x)=$ $\frac{1}{\sqrt{2 \pi}} \int_{x}^{\infty} e^{-\frac{u^{2}}{2}} d u=\frac{1}{2} \operatorname{erfc}\left(\frac{x}{\sqrt{2}}\right)$.

usuários a $P_{\epsilon}$ mínima será igual a $Q\left(\frac{A_{k}}{\sigma}\right)$. Na região da $P_{k}$ de interesse, a AME quantifica a perda de desempenho devido a existência de outros usuários ativos no canal. Portanto, $\eta_{k}$ não fornece nenhuma informação a respeito do desempenho do sistema sob forte ruído (região de baixa relação SNR).

Em contraste com a AME do filtro casado single-user, a eficiência assintótica ótima do k-ésimo usuário depende não só das correlações cruzadas com o usuário de interesse $\left\{\rho_{k j}, j \neq k\right\}$, mas também das correlações (auto e cruzada) dos interferentes $\left\{\rho_{l j}, l \neq k, j \neq k\right\}$. Para dois usuários síncronos e assíncronos (com janela de observação infinita) [7], a AME ótima, considerando $\rho_{\text {sinc }}=0,387$ (caso síncrono) e $\left|\rho_{12}\right|=0,3 \mathrm{e}\left|\rho_{21}\right|=0,5$ (caso assíncrono), é ilustrado na figura 4. Estão representados também as AME para o receptor Convencional e Ótimo síncronos e assíncronos. Note-se que para o canal síncrono tomouse a média geométrica das correlações cruzadas do canal assíncrono, $\rho_{\text {sinc }}=\sqrt{\left|\rho_{12}\right|\left|\rho_{21}\right|}$, a fim de tornar possível uma comparação numérica dos resultados. Para o caso de canal síncrono $\rho_{\text {sinc }}=\rho_{j k}=\rho_{k j}$ é válido sempre.

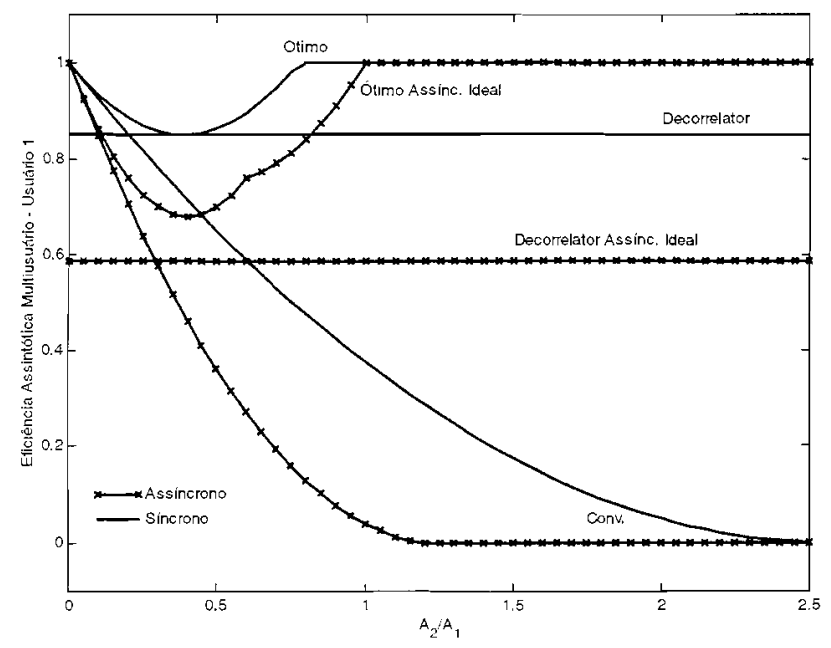

Figura 4. $A M E_{1}$ em função da amplitude relativa do usuário interferente com $\left|\rho_{12}\right|=0,3 ;\left|\rho_{21}\right|=0.5$ e $\rho_{\text {sinc }}=0.387$. Canal (As)Síncrono. Detectores Convencional, Descorrelacionador e Ótimo

\subsection{RESISTÊNCIA AO EFEITO NEAR-FAR, NFRES}

A resistência ao efeito near-far quantifica o grau de robustez do detector contra as disparidades de potência dos diversos usuários em um ambiente com MAI. Desigualdades de potência fazem com que usuários com potências pequenas no receptor sejam "sufocados" pelos usuários que chegam com maiores energias. A resistência near-far é definida como a AME de pior caso (inferior), relativo às energias de todos os usuários ativos: depende das formas de onda das sequiências de espalhamento e do demodulador [17].

$$
\bar{\eta}_{i}=\inf _{\substack{E_{j}>0 \\ j \neq k_{i}}} \eta_{k_{i}}
$$

onde $k$ é o usuário considerado e $j$ representando todos os demais usuários interferentes. 
Para o receptor Convencional síncrono, resulta:

$$
\bar{\eta}_{k}^{\text {Conv }}=\inf _{\substack{E_{j}>0 \\ j \neq k}} \eta_{k}= \begin{cases}1 & \text { se } \rho_{j k}=0 . j \neq k \\ 0 & \text { c.c. }\end{cases}
$$

Pode-se verificar facilmente através da figura 4 que a resistência ao efeito near-far do k-ésimo usuário é nula, exceto quando a correlação cruzada for igual a zero para todos os pares de usuários; ou seja, a $k$-ésima sequiência de espalhamento deve ser ortogonal a cada um dos sinais interferentes sobrepostos. E uma vez que esta condição não pode ser satisfeita para todos os atrasos, o receptor Convencional não é resistente ao efeito near-far.

Já para o receptor multiusuário Ótimo, a resistência ao efeito near-far para o h-źsino usuário será:

$$
\bar{\eta}_{k}^{\text {Opt }}=\left\{\begin{array}{l}
\frac{1}{\left[\mathbf{R}^{+}\right]_{k k}}=1-\mathbf{a}_{k}^{\top}\left(\mathbf{R}_{k}\right)^{-1} \mathbf{a}_{k} \\
\text { se k-ésimo sinal indep. } \\
\text { se } \mathbf{k} \text {-ésimo sinal } \in \\
\text { subespaço outros sinais }
\end{array}\right.
$$

onde: $[\bullet]_{k k}=$ denota seleção do kk-ésimo elemento da matriz $[\bullet] ; \mathbf{R}^{+}=$matriz inversa generalizada Moore-Penrose ${ }^{10}$ de $\mathbf{R}$; caso $\mathbf{R}$ seja não singular, $\mathbf{R}^{+}=\mathbf{R}^{-1}$; para o caso em que $\operatorname{det}(\mathbf{R})=\mathbf{0}$, a $\mathbf{R}^{+}$pode ser obtida pela decomposição dos valores singulares [17], [20], [21]. $\mathbf{R}_{k}=$ matriz de dimensão $(K-1) \times(K-1)$ resultante da eliminação da $k-$ ésima linha e coluna de $\mathbf{R} ; \mathbf{a}_{k}=$ vetor resultante da $\mathrm{k}$-ésima zluna de $\mathbf{R}$, eliminando-se o k-ésimo elemento desta couna. Dito de outra forma, $\mathbf{R}_{k}$ denota a matriz de correlação zntre os interferentes apenas, sem a $k$-ésima coluna e linha, $\operatorname{com} k=$ usuário de interesse; analogamente, $\mathrm{a}_{k}$ denota o vetor contendo apenas as correlações cruzadas entre o usuário de interesse e os interferentes.

Note que $\mathbf{R}_{k}$ também pode resultar singular devendo a NFRes ser obtida através da matriz Moore-Penrose. Para o caso de 2 usuários síncronos, a NFRes reduz-se a:

$$
\bar{\eta}_{k}^{O p t}=1-\rho^{2}
$$

resultando em um receptor resistente ao efeito near-far, a menos na condição das sequiências linearmente dependentes.

\section{DETECTORES MULTIUSUÁRIOS LINE- ARES}

Em um receptor linear multiusuário, a decisão de símbolo será feita empregando-se

$$
\hat{\mathbf{b}}=\operatorname{sgn}(\mathbf{z})
$$

onde: $\mathrm{z}=\mathrm{Ty}$; com $\mathrm{y}=$ saídas do banco de filtros casados; $\mathrm{T}=$ matriz de transformação linear, figura $2 \mathrm{~b}$. Para o usuário h, a estimativa de símbolo será:

$$
\hat{b}_{k}=\operatorname{sgn}\left(z_{k}\right)
$$

com

$$
z_{k}=\mathbf{t}_{k}^{H} \mathbf{y}=\mathbf{c}_{k}^{H} \mathbf{r},
$$

\footnotetext{
${ }^{10}$ Também denominada matriz Pseudo Inversa de $\mathbf{R}$.
}

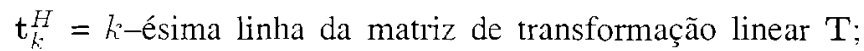
$\mathbf{c}_{k}^{H}=$ vetor de coeficientes de um filtro equivalente operando diretamente sobre o sinal recebido.

Tanto a matriz de transformação como os coeficientes do filtro são selecionados visando minimizar algum critério de custo. No receptor CDMA Convencional faz-se o conjunto de coeficientes igual ao código de espalhamento, portanto $c \in$ $\{+1,-1\}$. Enquanto que no Descorrelacionador selecionase $\mathrm{c}$ de tal forma a eliminar a MAI e no receptor MMSE os coeficientes são selecionados objetivando minimizar o erro quadrático médio total. assumindo. nestes casos. valoras :aals. Ial munmuzação poue ser ielta soore todos os usuários (multiusuário) ou considerando apenas um (single-user), de modo descentralizado onde apenas o usuário de interesse necessita ser demodulado em um filtro casado modificado. No entanto, este filtro depende das correlações cruzadas dos sinais dos usuários ativos (e das SNRs, no caso do detector MMSE) e do cálculo da resposta impulsiva do canal, que implica em inversão de matriz.

\subsection{DETECTOR MULTIUSUÁRIO LINEAR DESCORRELACIONADOR}

O Descorrelacionador aplica a matriz de correlação inversa $\mathbf{T}=\mathbf{R}^{-1}$ à saída do detector Convencional objetivando o desacoplamento dos sinais dos usuários interferentes, resultando em um receptor resistente ao efeito near-far [4], [17], [22], enquanto que o detector Convencional da figura 2.b, obtém as decisões de bits realizando-se a transformação linear $\mathbf{T}=\mathbf{I}_{N^{\prime}}$ em y. O desempenho do Descorrelacionador não é afetado pelas disparidades de potência dos usuários, possibilitando a detecção sem o conhecimento das amplitudes dos sinais recebidos.

A transformação linear de descorrelação é a projeção do sinal do usuário desejado em um espaço ortogonal àquele definido pelos sinais interferentes. A estimativa de dados é obtida através de:

$$
\hat{\mathbf{b}}=\operatorname{sgn}(\mathrm{T} \mathbf{y})=\operatorname{sgn}\left(\sqrt{\mathbf{E}} \mathbf{b}+\mathbf{R}^{-1} \mathbf{n}\right) .
$$

As principais vantagens associadas à implementação do Descorrelacionador são:

1. significativo aumento de desempenho / capacidade em relação ao detector Convencional;

2. não necessita estimativa das amplitudes recebidas;

3. menor complexidade computacional que o detector Ótimo: linear com número de usuários;

4. corresponde ao detector Ótimo quando as energias de todos os usuários não são conhecidas no receptor: produz estimativa conjunta de máxima verossimilhança para os bits transmitidos e suas respectivas amplitudes recebidas:

5. Produz valores ótimos de desempenho para ambiente com forte efeito near-far;

6. Em sistemas Síncronos é capaz de descorrelacionar um bit por vez: para o bit $\mathrm{k}$, necessita-se apenas aplicar a 
k-ésima linha de $\mathbf{R}^{-1}$ para estimar a saída do banco de filtros casados.

No entanto, existem desvantagens associadas à implementação do Descorrelacionador:

1. Aumento do ruído, similar ao equalizador zero-forcing: a potência associada ao termo de ruído, $\mathbf{R}^{-1} \mathbf{n}$, à saída do Descorrelacionador, é sempre maior ou igual a potência associada ao termo de ruído à saída do detector Convencional, para cada bit;

2. Excessivo tempo para computar a inversão de $\mathbf{R}$, tornando difícil o cálculo em tempo real;

3. Em sistemas Assíncronos, a matriz de correlação (26) terá dimensão da ordem de $\mathcal{M} . K$, grande demais para uma mensagem típica de comprimento $\mathcal{M}$. Este problema é contornado truncando-se a janela de observação para algumas unidades ou dezenas de bits, resultando em alguma perda de desempenho.

\subsection{DETECTOR MULTIUSUÁRIO LINEAR MMSE}

Incorporando-se informações sobre as SNRs à matriz de transformação linear, o MUD assim obtido terá algum ganho de desempenho em relação ao Descorrelacionador, pois leva em conta o ruído de fundo (aleatório) no processo de detecção; em contrapartida, a estimativa para o vetor de dados necessita conhecer as potências de todos os sinais recebidos, o de interesse e os interferentes. O detector MMSE substitui a transformação do Descorrelacionador por:

$$
\mathbf{T}=\left[\mathbf{R}+\sigma_{n}^{2} \mathbf{A}^{-2}\right]^{-1}
$$

com a matriz diagonal dada por

$$
\sigma_{n}^{2} \mathbf{A}^{-2}=\operatorname{diag}\left\{\frac{\sigma_{n}^{2}}{A_{1}^{2}} \cdot \frac{\sigma_{n}^{2}}{A_{2}^{2}} \ldots \frac{\sigma_{n}^{2}}{A_{K^{2}}^{2}}\right\}
$$

que minimiza o erro quadrático médio entre os dados transmitidos e a saída do detector Convencional e maximiza a SNR à saída do detector MMSE:

$$
\min E\left[(\mathbf{z}-\mathbf{b})^{H}(\mathrm{z}-\mathrm{b})\right] \text {. }
$$

O problema da minimização do erro quadrático médio (44) pode ser resolvido como uma otimização em um espaço de dimensão finita através da escolha adequada do vetor transformação, $\mathbf{t}_{k}, K \times 1$, de tal forma a minimizar

$$
E\left[\left(b_{k}-\mathbf{t}_{k}^{H} \mathbf{y}\right)^{2}\right]
$$

resultando em $K$ problemas de otimização desacoplados (um para cada usuário), que podem ser resolvidos simultaneamente escolhendo-se adequadamente a matriz de transformação T, $K \times K^{r}$,

$$
\min _{\mathrm{T} \in \Re^{K^{K} \times K}} E\left[\| \mathrm{b}-\left.\mathrm{Ty}\right|^{2}\right]
$$

cuja média é tomada em relação ao vetor de bits transmitido, b, e o vetor ruído em y, (10), é AWGN com matriz de covariância igual a $\sigma_{n}^{2} \mathbf{R}$. As saídas do detector linear MMSE seguem as decisões:

$$
\hat{b}_{k}=\operatorname{sgn}\left(\left[\mathbf{R}+\sigma_{n}^{2} \mathbf{A}^{-2}\right]^{-1} \mathbf{y}\right)_{k} .
$$

Outra formulação para o problema MMSE consiste em substituir b de (46) por $\mathrm{Ab}$, equivalente a tentar reproduzir $A_{k} b_{k}$ ao invés de $b_{k}$ à saída da transformação linear. Como as amplitudes $A_{k}$ são assumidas conhecidas no MMSE, a solução para este problema de otimização conduz à mesma transformação de (42).

Enquanto o receptor Convencional é otimizado para tratar exclusivamente o AWGN, o Descorrelacionador elimina a MAI, descuidando do ruído de fundo. Em contraste, o detector linear MMSE pode ser visto como uma solução de compromisso que leva em conta tanto o AWGN quanto a MAI. De fato, ambos os receptores, o Convencional e Descorrelacionador, são casos limites do detector MMSE:

1. mantendo-se a amplitude do usuário de interesse fixa, $A_{1}$, tomando-se $A_{2}, A_{3}, \ldots A_{K} \rightarrow 0$, a primeira linha de $\left[\mathbf{R}+\sigma_{n}^{2} \mathbf{A}^{-2}\right]^{-1}$ tende a $\left[\frac{A_{1}^{2}}{A_{1}^{2}+\sigma_{n}^{2}}, 0, \ldots, 0\right]$, que corresponde ao filtro casado para o usuário 1; ou quando $\sigma_{n}$ cresce, $\left[\mathbf{R}+\sigma_{n}^{2} \mathbf{A}^{-2}\right]^{-1}$ torna-se uma matriz diagonal; portanto, o detector MMSE tende ao detector Convencional quando $\sigma_{n} \rightarrow \infty$.

2. caso todas as amplitudes sejam mantidas fixas e tomando-se $\sigma_{n} \rightarrow 0$ (região de alta $E_{b} / N_{0}$ ), a transformação linear para o detector linear MMSE tende a:

$$
\left[\mathbf{R}+\sigma_{n}^{2} \mathbf{A}^{-2}\right]^{-1} \rightarrow[\mathbf{R}]^{-1}
$$

Como desvantagem, o detector MMSE requer estimação das amplitudes e seu desempenho depende das potências dos usuários interferentes.

\subsection{DESEMPENHO PARA O DESCORRELA- CIONADOR E MMSE: AME, NFRES E $P_{E}$}

Foi mostrado em [6] e [17] que a AME para o k-ésimo usuário em um Descorrelacionador síncrono independe tanto do nível do ruído quanto das amplitudes dos interferentes e portanto resulta igual à resistência ao efeito near-far:

$$
\left.\bar{\eta}_{k}^{\text {Decor }}=\eta_{k}^{\text {Decor }}=\frac{1}{\left[\mathrm{R}^{+}\right]_{k k}} \quad \text { (Sínc. }\right) .
$$

Observa-se que o Descorrelacionador síncrono obtém resistência ao efeito near-far idêntica ao detector multiusuário Ótimo (36), figura 4. A eficiência assintótica do Descorrelacionador independe da relação de amplitudes dos usuários interferente/interesse. É menor que a eficiência assintótica do detector Convencional quando o interferente for suficientemente fraco. Para dois usuários, esta condição é dada por

$$
\frac{A_{2}}{A_{1}} \leq \frac{1-\sqrt{1-\rho_{12}^{2}}}{\left|\rho_{12}\right|}
$$


Quando a amplitude interferente for pequena o suficiente, o detector Convencional será preferível ao Descorrelacionador. A razão é que embora as componentes devidas ao usuário de interesse, nas respectivas estatísticas de decisão, sejam idênticas enı ambos os casos, a componente devido ao ruído tem variância $\sigma^{2}$ no detector Convencional contra $\frac{\sigma^{2}}{1-\rho_{12}}$ no Descorrelacionador. Portanto, o preço pago pela completa eliminação da MAI é, neste caso, um acréscimo de ruído. A AME do Descorrelacionador síncrono será igual à AME de pior caso do detector Ótimo no ponto $A_{2}=\left|\rho_{12}\right| A_{1}$, figura 4.

A grande vantagem de se empregar o Descorrelacionador está no fato de se combater otimamente o efeito near-far, de não requerer conhecimento das amplitudes interferentes e de atingir o mesmo grau de robustez contra desajustes nas amplitudes recebidas que o obtido com detectores ótimos de complexidade exponencial; porém no Descorrelacionador a complexidade computacional por bit demodulado é similar àquela do detector Convencional.

A Equação (48) mostra que o detector MMSE converge para o Descorrelacionador quando as amplitudes são mantidas fixas e a SNR tende a infinito. Este fato implica que o MMSE possui a mesma eficiência assintótica e resistência to efeito near-far do Descorrelacionador. Em particular, o MMSE também alcança resistência ótima ao efeito near-far.

Madhow e Honig [23] caracterizaram a resistência ao efeito near-far do detector MMSE em função do ganho de processamento e número de usuários, assumindo seqüências aleatórias. Mostraram que para um canal DS-CDMA sem controle de potência, o número de usuários simultâneos, $h$. cresce linearmente com o ganho de processamento, $N$. Esta modelagem é válida com as seguintes restrições: a) população de usuários estacionária; b) ausência de variações de parâmetros de canal. A figura 5 mostra os limites superior e inferior para a resistência ao efeito near-far média -... sistemas A- e S-CDMA com seqüencias de espalhamento aleatórias de comprimento $N=31$ (Rndz31), em função do número de usuários ativos. Como o limite inferior e superior são muito próximos, pode-se obter a seguinte regra de projeto para sistemas DS-CDMA: o desempenho de um detector MMSE com filtro de comprimento igual ao ganho de processámento, $N$, será resistente ao efeito near-far caso satisfaça:

$$
F-1<N \quad \text { (sínc), } \quad K-1<\frac{N}{2} \quad \text { (assínc.). }
$$

Nestes casos, todos os $K-1$ interferentes possuem potência maior que o usuário de interesse.

Em receptores multiusuário lineares, a expressão geral para a BER será afetada pela resistência ao efeito near-far:

$$
P_{k}^{M U D \_l i n}=Q\left(\sqrt{\frac{E_{k} \bar{\eta}_{k}}{\sigma_{\eta}^{2}}}\right) .
$$

Particularmente, para o Descorrelacionador e o MMSE síncronos com $\mathrm{K}$ usuários. a BER pode ser expressa, respectivamente, por:

$$
P_{k}^{\text {Decor }}=Q\left(\frac{A_{k}}{\sigma_{n \sqrt{ }\left[\mathbf{R}^{+}\right]_{k i k}}}\right)
$$

$$
\tilde{P}_{1}^{M M S E}=Q\left(\frac{A}{\sigma_{n}} \sqrt{1-\frac{\rho^{2}(K-1)}{1+\left(\frac{\sigma_{n}}{A}\right)^{2}+\rho(K-2)}}\right) .
$$



Figura 5. Limites superior $(-\star-)$ e inferior $(-)$ para $o$ desempenho near-far do MMSE considerando seqüências aleatórias.

A expressão para o MMSE síncrono (54) é aproximada e válida apenas para sinais com energias idênticas e equicorrelacionados, isto é $\rho_{k j}=\rho . \forall k \neq j$ [24]. Para o receptor Convencional, a probabilidade de erro de bit exata para o k-ésimo usuário é obtida combinando-se os padrões de erros de bits possíveis para todos os interferentes (binomial), resultando em um cálculo dispendioso quando o número de usuários crescer além de algumas dezenas.

A figura 6 mostra a probabilidade de erro de bit média para o sistema Convencional, Descorrelacionador e MMSE nos casos de 28 e 11 usuários síncronos com e sem controle perfeito de potência e sequiências de Gold de comprimento igual a 31 (Gold31). Os desempenhos do Descorrelacionador e do MMSE são muito próximos para a maioria dos casos práticos de interesse e superiores ao Convencional. O MMSE terá desempenho levemente superior ao Descorrelacionador nos casos de sistemas altamente carregados, figura 6.a, ou quando os interferentes forem fracos.

Não se conhece expressão fechada para o detector Ótimo. Limitantes para a taxa de erro de bit do detector Ótimo foram dadas em [4], [6], [25], [26]. Para dois usuários síncronos, os limites inferior e superior da probabilidade de erro de bit em função do desajuste de potência são mostrados na figura 7. Observe-se ainda que os MUD lineares MMSE e Descorrelacionador são resistentes ao efeito near-far, mesmo para grandes disparidades de potência e elevadas correlações cruzadas entre o usuário de interesse e os interferentes. Apenas quando a amplitude do interferente for suficientemente menor que a do usuário de interesse (neste caso, $\frac{A_{2}}{A_{1}} \lesssim-7$ $\mathrm{dB}$ ), o Descorrelacionador apresentará pior desempenho que o detector Convencional. Na região onde a potência do ruído de fundo é maior ou as energias dos interferentes tendem a desaparecer, o MMSE resulta em melhor desempenho que o Descorrelacionador, uma vez que a transformação linear para - Descorrelacionador realça o ruído de fundo.

Nas figuras 8 e 9 são apresentados alguns resultados comparativos de desempenho médio para os receptores Convencional, Descorrelacionador e MMSE com seqüências de Gold 
e aleatórias. Independente da família de seqüências utilizada, há uma sensível redução na taxa de erro de bit quando se emprega MUD linear MMSE ou Descorrelacionador em relação ao receptor Convencional, embora um melhor desempenho seja alcançado com as sequiências de Gold, devido à otimização dos valores das autocorrelações e cruzadas.
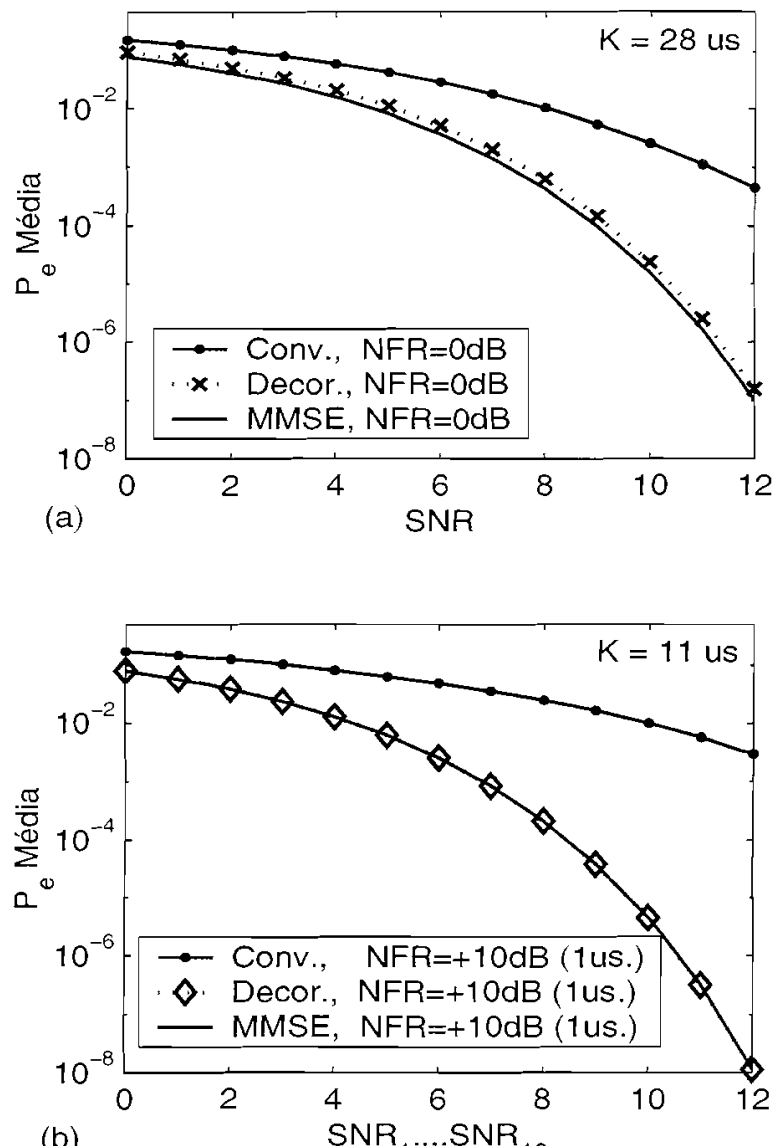

(b)

$$
\mathrm{SNR}_{1} \ldots \mathrm{SNR}_{10}
$$

Figura 6. $\overline{B E R}$ para detectores Convencional, Descorrelacionador e MMSE Síncronos: seqüências de Gold31. a) $K=28$ usuários, controle perfeito de potência: b) $K=11$ usuários, todos usuários de mesma potência, exceto o último, com $10 d B$ acima dos demais.

Na Figura 8 obteve-se a $\overline{P e}$ sobre usuários síncronos considerando Gold31, $\frac{E_{b}}{V_{G}}=10 \mathrm{~dB}$ e população de usuários crescente. A imunidade do Descorrelacionador e do MMSE na condição de forte near-far é mostrada na Figura 8.a; obtevese o desempenho médio sobre a metade da população de usuários fracos interferentes. Perceba que o efeito do desajuste de potência é devastador para o desempenho do receptor Convencional. Já a Figura 8.b apresenta o comportamento dos detectores na condição de controle perfeito de potência. Observe ainda que não há diferença significativa entre os desempenhos do Descorrelacionador e MMSE nas condições de controle perfeito de potência $(N F R=0 d B$ ) e quando há forte efeito near-far ( NFR $=+9 d B)$.

Desempenho levemente melhorado do MMSE em relação ao Descorrelacionador pode ser comprovado na Figura 9. Foram consideradas sequeeencias aleatórias Rndz32 e 11 usuários perfeitamente sincronizados, sendo cinco usuários interferentes $(u \overline{7}, u 8, \ldots u 11)$ com mesma potência recebida e consti-

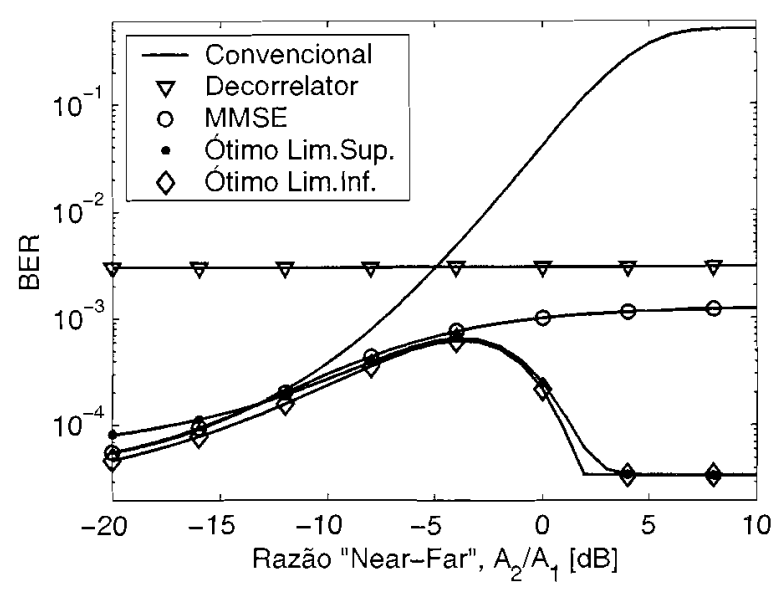

Figura 7. Comparação da BER para os detectores Convencional, Descorrelacionador, MMSE e Ótimo. 2 usuários síncronos com desajuste de potência NFR $\in[-20,10] \mathrm{dB}$ e correlação cruzada $\rho=0.65 . \mathrm{SNR}_{1}=12 \mathrm{~dB}$

tuindo três situações de interferência: $N F R=-20$ ou 0 ou $+\check{\partial} d B$. Demais usuários interferentes $(u 2, u 3, \ldots u 6)$ apresentam a mesma condição de $\frac{E_{b}}{N_{0}}$ do usuário de interesse (u1). Note-se que o desempenho do Descorrelacionador na condição síncrona independe das amplitudes recebidas, enquanto que o MMSE terá seu desempenho levemente melhorado quando os interferentes forem fracos $(N F R=-20$ dB). Para qualquer situação de $N F R$, ter-se-á $\overline{P e}^{M M S E} \leq$ $\overline{P e}^{\text {Decor. }}$.

\subsubsection{AME E NFRES - CASO ASSÍNCRONO}

$O$ vetor saída do filtro casado, com representação em tempo discreto, em um receptor DS/CDMA de canal assíncrono (21) pode ser representado no domínio $z$ transformado (notação para sistemas amostrados, [27], [20]) como

$$
\mathbf{S}(z)=\mathbf{R}^{H}[1] z+\mathbf{R}[0]+\mathbf{R}[1] z^{-1}
$$

com o respectivo vetor $\widetilde{\mathbf{n}}[i]=$ variável Gaussiana independente com matriz de covariância $\sigma^{2}$ I. Assim, analogamente ao Descorrelacionador Síncrono, uma escolha natural para a transformação linear capaz de recuperar os bits transmitidos será tomar a inversa da função de transferência do canal em tempo discreto. Portanto a transformação linear para o Descorrelacionador assíncrono será

$$
\mathbf{T}=\left(\mathbf{R}^{H}[1] z+\mathbf{R}[0]+\mathbf{R}[1] z^{-1}\right)^{-1}
$$

resultando na AME e NFRes para o k-ésimo usuário em um Descorrelacionador assíncrono

$$
\begin{aligned}
& \bar{\eta}_{k}^{\text {Decor }}=\eta_{k}^{\text {Decor }}= \\
& \quad \frac{1}{\frac{1}{2 \pi} \int_{-\pi}^{\pi}\left[\mathbf{R}^{H}[1] z+\mathbf{R}[0]+\mathbf{R}[1] z^{-1}\right]_{k k}^{+} d \omega} .
\end{aligned}
$$

A probabilidade de erro de bit é imediatamente obtida de (52).

Analogamente, o detector linear MMSE assíncrono será um filtro linear invariante no tempo de $K$ entradas e $I^{*}$ saídas 

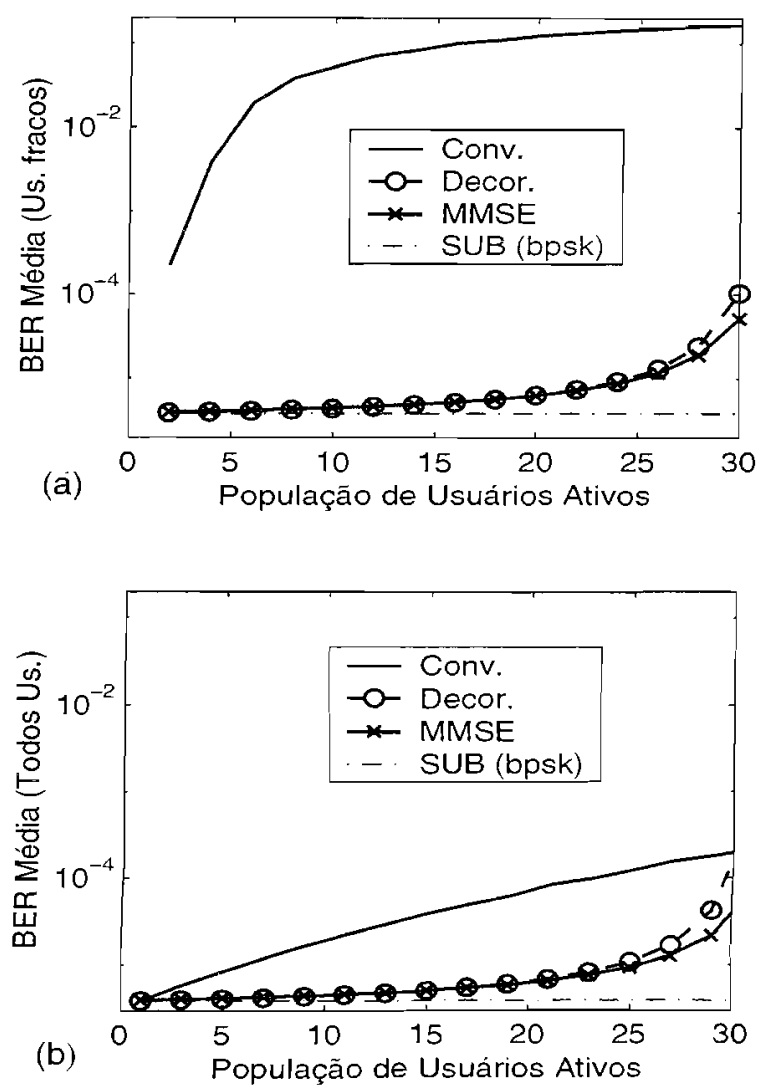

Figura 8. Desempenho médio para os receptores Convenci?nal, Descorrelacionador e MMSE síncronos em função da população crescente de usuários. (a) metade dos usuários : $N F R=9 d B$; (b) controle perfeito de potência receiida. $\frac{E_{b}}{N_{0}}=10 \mathrm{~dB}$ e Gold 31

₹ função de transferência

$$
\mathbf{T}=\left(\mathbf{R}^{H}[1] z+\mathbf{R}[0]+\sigma_{n}^{2} \mathbf{A}^{-2}+\mathbf{R}[1] \tilde{z}^{-1}\right)^{-1} .
$$

E uma vez que o MMSE converge para o Descorrelacionador quando $\sigma \rightarrow 0$, então a AME e NFRes do detector MMSE 氵ão idênticas e iguais às do Descorrelacionador, tanto para o caso síncrono (49), como o assíncrono (57).

\subsubsection{EFEITO DO TAMANHO DA JANELA DE OBSERVAÇÃO $\mathcal{M}$ SOBRE A AME E NFRES NO DESCORRELACIONADOR}

Detectores lineares assíncronos que utilizam inversão da matriz de correlação para obter o desacoplamento da MAI, zomo o Descorrelacionador e o MMSE, idealmente necessitariam operar sobre toda a mensagem, a qual, para os casos práticos, é muito grande ou mesmo pode ser considerada ininita. Para o Descorrelacionador Assíncrono Ideal [7], o rezeptor resulta em um filtro com resposta impulsiva infinita IIR), o qual deve processar a sequiència total do sinal recebido.

A detecção de usuários assíncronos genéricos, com $\tau_{k} \in$ - $T, T]$ não ordenados, pode ser interpretada como cada símbolo sendo transmitido por usuários virtuais distintos em um canal síncrono no intervalo $[-M T, M T+2 T]$. similar ao apresentado na Figura 3.b, porém incluindo atrasos

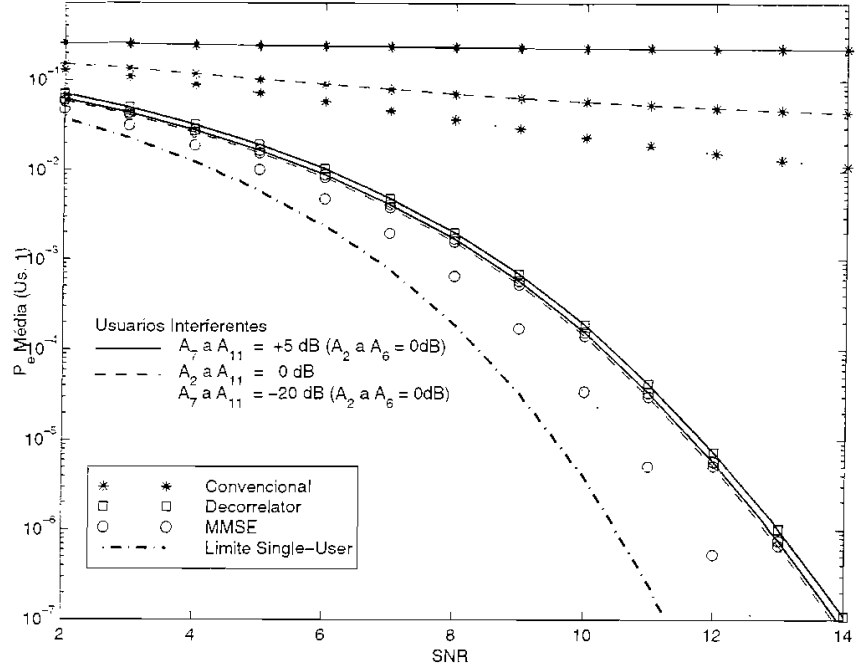

Figura 9. $\overline{B E R_{1}} \times S N R$ para receptores Convencional, Descorrelacionador e MMSE. 11 usuários síncronos considerando sequências aleatórias (35 realizações) e $N=32$ Metade dos usuários interferentes (cinco) com $N F R=+\bar{\jmath}$ ou 0 ou $-20 \mathrm{~dB}$.

negativos. No caso de $K$ usuários assíncronos, aplica-se um método de detecção similar ao caso síncrono, porém expande-se a janela de observação sobre toda a mensagem transmitida, $\mathcal{M}=2 M+1$, para todas as entradas dos $K$ usuários. Tem-se então o equivalente a $(2 N I+1) K$ usuários virtuais síncronos. Quando $\mathcal{M} \rightarrow \infty$, a NFRes do Descorrelacionador assíncrono de (57) assumirá valor idêntico ao da resistência ao efeito near-far do Descorrelacionador síncrono (49). No entanto, para os casos realistas de interesse, $\mathcal{M}$ é muito grande, resultando em complexidade computacional elevada, tornando inviável a inversão da matriz de correlação normalizada, (26), com dimensão da ordem de $(2 M+1) K$, ben como introduz atrasos de processamento intoleráveis. Note que a matriz de correlação deve ser atualizada ou recalculada sempre que ocorrer pelo menos uma das seguintes mudanças: a) ativação ou desativação de usuário; b) mudanças nos atrasos de propagação de pelo menos um usuário ativo ${ }^{11}$.

Como o atraso e complexidade de processamento inviabilizam este processamento, adotam-se janelas de observação finitas: são os MUD Lineares Assíncronos Truncados. $\mathrm{O}$ desempenho obtido com um MUD truncado é inferior ao correspondente ideal $(\mathcal{M} \rightarrow \infty)$. Porém, em geral, para a maioria dos detectores truncados com janela de observação de alguns períodos de bits obtém-se desempenho próximo ao ideal. Alternativas para o Descorrelacionador Assíncrono Ideal incluem o Descorrelacionador Aproximado [17] e a abordagem One-Shot, versão fixa [25] e adaptativa [28]. O Descorrelacionador Assíncrono One-Shot realiza a detecção multiusuário a partir da observação truncada dos sinais dos usuários, ignorando toda informação fora deste intervalo. Variações da abordagem One-Shot incluem Sliding Windows [29], [30], Descorrelacionador Auxiliado por Decisão de Bit das Bordas (Edge Decision Assisted Descorrelacionador, EDAD) [31],

\footnotetext{
${ }^{11}$ Devido à mobilidade e/ou multipercurso do sinal
} 
Detector de Inserção de Bit Isolado (Isolation Bit Insertion, IBI), [32], [33] e o Descorrelacionador Linear Assíncrono de Comprimento de Memória Finita [34], [35].

A solução Descorrelacionador Assíncrono Truncado que segue a abordagem síncrona com usuários virtuais é subótima com complexidade por bit demodulado similar àquela do caso síncrono, $\mathcal{O}\left(K^{3}\right)$, porém independente do tamanho da mensagem, conduzindo a soluções factíveis quando o número de usuários não for muito elevado. A razão para a existência de tal algoritmo se deve às características da matriz de correlação normalizada $\mathfrak{R}$ em (26). Cada símbolo sobrepõe-se a apenas dois símbolos consecutivos de cada usuário distinto. Seja o exemplo da Figura 3, para o caso de $K=2$ usuários ativos e tamanho da janela de observação truncada $\mathcal{M}=5$. A matriz de correlação normalizada correspondente será

$$
\boldsymbol{R}=\left[\begin{array}{ccccccc}
1 & \rho_{12} & 0 & 0 & \cdots & 0 & 0 \\
\rho_{12} & 1 & \rho_{21} & 0 & \cdots & 0 & 0 \\
0 & \rho_{21} & 1 & \rho_{12} & \cdots & 0 & 0 \\
0 & 0 & \rho_{12} & 1 & \ddots & 0 & 0 \\
\vdots & \vdots & \vdots & \ddots & \ddots & \vdots & \vdots \\
0 & 0 & 0 & \cdots & \rho_{21} & 1 & \rho_{12} \\
0 & 0 & 0 & \cdots & 0 & \rho_{12} & 1
\end{array}\right]_{10 \times 10}
$$

com as correlações cruzadas par e ímpar dadas por (22) e (23). Aumentando-se a janela de observação, resulta em melhoria de desempenho acompanhado de complexidade computacional adicional.

No Descorrelacionador Assíncrono Truncado One-Shot$1 T$ de [25], ao contrário de se observar uma quantidade considerável de intervalos de símbolos, os sinais são demodulados e decisões são feitas baseadas em apenas um único intervalo de símbolo, $\mathcal{M}=1$. Descarta-se toda informação fora da janela de observação $[0, T]$. A matriz de correlação terá dimensão $^{12}\left(2 h^{\top}-1\right) \times\left(2 h^{\circ}-1\right)$ e o Descorrelacionador OneShot-IT resultante terá a vantagem de redução na complexidade de implementação, porém com as seguintes desvantagens:

- pior BER, AME e NFRes quando comparado ao Descorrelacionador Assínciono Ideal:

- a matriz $\mathbf{R}^{\text {OShot_1T }}$ pode resultar singular, mesmo se a condição de realização estável para o filtro do Descorrelacionador (zero forcing equalizer) existir, $\operatorname{det}\left[\mathbf{R}^{\boldsymbol{T}}[1] e^{j \omega}+\mathbf{R}[0]+\mathbf{R}[1] e^{-j \omega}\right] \neq 0$ para todo $\omega \in[0,2 \pi]$;

- devido ao processamento truncado (duração $1 T$ ), os elementos de correlação de $\mathbf{R}^{O S h o t-1 T^{\prime}}$ serão fortemente afetados pelas energias parciais dos sinais interferentes, $\varepsilon_{k}$, requerendo filtros casados parciais aos bits interferentes.

A eficiência assintótica e a resistência ao efeito near-far para o $k$-ésimo usuário do Descorrelacionador One-Shot-1T são idênticas e dadas pelo inverso do $k$-ésimo elemento da diagonal principal da inversa da matriz de correlação ${ }^{13}$. Para

\footnotetext{
${ }^{12}$ Supondo perfeito sincronismo com o usuário de interesse

${ }^{13} \mathrm{Ou}$ matriz inversa generalizada de Moore-Penrose.
}

dois usuários, a matriz de correlação e a NFRes para o primeiro resultam em:

$$
\begin{aligned}
& \mathbf{R}^{\text {OShot } 1 T}=\left[\begin{array}{ccc}
1 & \frac{\rho_{21}}{\sqrt{e_{2}}} & \frac{\rho_{12}}{\sqrt{1-e_{2}}} \\
\frac{\rho_{21}}{\sqrt{\varepsilon_{2}}} & 1 & 0 \\
\frac{\rho_{12}}{\sqrt{1-e_{2}}} & 0 & 1
\end{array}\right]_{(2 \hbar-1) \times(2 K-1)} \\
& \bar{\eta}_{1}^{\text {OShot } 1 T}=\frac{1}{\left[\mathbf{R}^{\text {OShot } 1 T+]_{11}}\right.}=1-\frac{\rho_{12}^{2}}{1-\varepsilon_{2}}-\frac{\rho_{21}^{2}}{\varepsilon_{2}} .
\end{aligned}
$$

De (61) conclui-se que o desempenho do Descorrelacionador One-Shot-1T dependerá, além das correlações cruzadas, também das energias parciais dos sinais interferentes. A probabilidade de erro de bit para o Descorrelacionador OneShot-1T é obtida imediatamente de (61) em (52).

O Descorrelacionador Assíncrono Ideal terá desempenho assintótico resultante da média geométrica das correspondentes NFRes síncronas cujos elementos de correlação são dados pela soma e subtração das correlações cruzadas periódica par e ímpar. Para dois usuários, de (57), resulta:

$$
\begin{aligned}
& \bar{\eta}_{1}^{\text {DecorAs } I \text { deal }}= \\
& \quad=\sqrt{\left[1-\left(\rho_{12}+\rho_{21}\right)^{2}\right]\left[1-\left(\rho_{12}-\rho_{21}\right)^{2}\right]} .
\end{aligned}
$$

O desempenho do Descorrelacionador Assíncrono Ideal supera o do Descorrelacionador One-Shot-1T, uma vez que aquele considera janela de observação infinita e portanto não é afetado pelos erros de decisão dos bits de borda que qualquer Descorrelacionador de janela truncada apresenta. Assim, o Descorrelacionador Assíncrono Ideal deve ser utilizado como referência quando se avalia o desempenho de novas propostas de Descorrelacionadores truncados.

Para se ter uma idéia da perda de desempenho do Descorrelacionador One-Shot IT em relação ao Ideal, considere um sistema com seqüências de espalhamento de Gold7, 5 usuários com atrasos $\left[(0,1,2,3,4) T_{c}\right]$. esquematizado na Figura 10. O resultado da resistência ao efeito near far para o primeiro usuário do Descorrelacionador One-Shot-1T e diferentes números de interferentes pode ser comparado na tabela 2 ao desempenho do Descorrelacionador Assíncrono Ideal. Note-se a redução da NFRes com o aumento do número de usuários, $K$, para ambos Descorrelacionadores assíncronos, bem como a degradação de desempenho do Descorrelacionador One-Shot_lT em relação ao de janela infinita.

Comparando-se o efeito da janela de observação sobre a NFRes em um Descorrelacionador Assíncrono Truncado, verifica-se que o desempenho tende rapidamente ao do Descorrelacionador Ideal quando $\mathcal{M}$ atinge alguns períodos de bits. Considere as primeiras quatro seqüências de espalhamento da Figura 10 e $\mathcal{M}=1,2,3,4$ bits; as respectivas NFRes para o primeiro usuário são mostradas na Tabela 3. Note que a NFRes para a janela de observação igual a 4 bits é praticamente a mesma daquela obtida anteriormente para o Descorrelacionador Ideal. Tabela 2, indicando a convergência de resultados quando a janela de observação cresce. Neste caso, a eficiência assintótica de um Descorrelacionador assíncrono para o i-ésino bit do $h$-ésimo usuário é calculada assumindo-se que a mensagem transmitida apresenta comprimento finito [7], sendo dada pelo ( $k . i)$-ésimo elemento da 


\begin{tabular}{|c|c|c|}
\hline$K$ & $\bar{\eta}_{1}^{\text {OShot_1T }}$ eq (61) & $\bar{\eta}_{1}^{\text {Dec.As.Ideal }}$ eq (57) \\
\hline \hline 2 & 0,4762 & 0.63232 \\
\hline 3 & 0,3778 & 0.57571 \\
\hline 4 & 0,3095 & $\mathbf{0 . 5 0 6 6 5}$ \\
\hline 5 & 0,2334 & 0,41134 \\
\hline
\end{tabular}

Tabela 2. Resistência ao efeito Near-Far: Descorrelacionador Ideal e One-Shot_lT para número de usuários distintos.

diagonal da inversa de (26),

$$
\eta_{k, i}^{\text {DecAssínc }}=\frac{1}{\mathfrak{R}_{(k, i)(k, i)}^{-1}}
$$

com

$$
\begin{aligned}
& \mathbf{R}(0)=\left[\begin{array}{cccc}
1 & -\frac{4}{7} & \frac{1}{7} & 0 \\
-\frac{4}{7} & 1 & -\frac{4}{7} & \frac{3}{7} \\
\frac{1}{7} & -\frac{4}{7} & 1 & -\frac{2}{7} \\
0 & \frac{3}{7} & -\frac{2}{7} & 1
\end{array}\right] \\
& \mathbf{R}(1)=\left[\begin{array}{cccc}
0 & 0 & 0 & 0 \\
-\frac{1}{7} & 0 & 0 & 0 \\
\frac{2}{7} & -\frac{1}{7} & 0 & 0 \\
-\frac{1}{7} & 0 & \frac{1}{7} & 0
\end{array}\right]
\end{aligned}
$$

e $\mathfrak{R}$, neste caso, matriz quadrada de dimensão $4,8 \cdot 12,16$ para os respectivos $\mathcal{M}$.

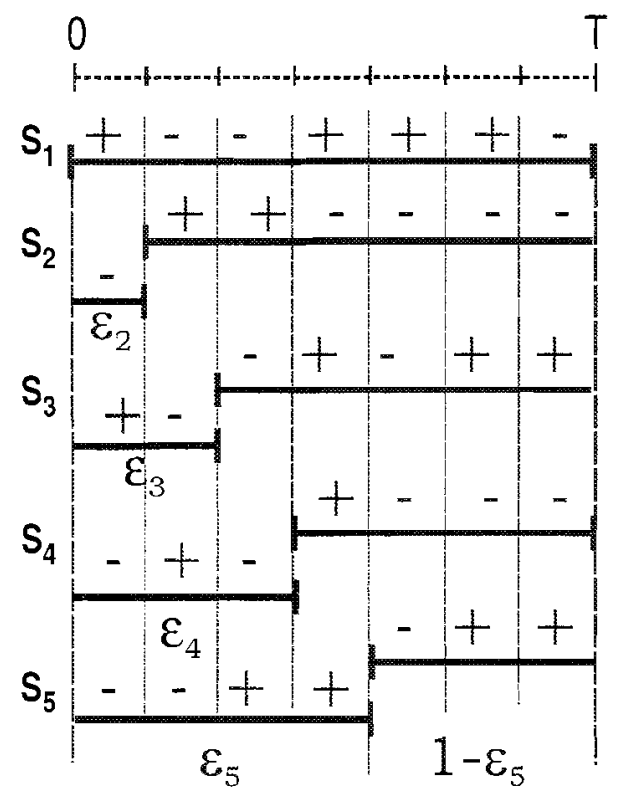

Figura 10. Correlações e Energias Parciais para o Descorrelacionador One-Shot_IT, Gold7.

A resistência near-far corresponderá ao pior caso da eficiência assintótica:

$$
\bar{\eta}_{k}^{\text {DecAssinc }}=\frac{1}{\max _{i}\left\{\Re_{(k . i)(k . i)}^{-1}\right\}} .
$$

Observe que na deteç̧ão de um Descorrelacionador Assíncrono Truncado não são considerados os efeitos dos bit de bordas ${ }^{14}$ dos usuários interferentes; além disto, a hipótese simplificadora de mensagem finita de comprimento $\mathcal{M}$ conduz a NFRes irrealistas quando a janela de observação for muito pequena $(\mathcal{M}=1)$.

\begin{tabular}{|c|c|}
\hline $\mathcal{M}$ & $\bar{\eta}_{1}^{\text {DecAssinc }}\left(K_{-}=4 u s\right)$ \\
\hline 1 & $0 . \overline{5} 562 t$ \\
\hline 2 & 0.51889 \\
\hline 3 & 0.50810 \\
\hline 4 & 0,50736 \\
\hline \multicolumn{2}{|c|}{$\bar{\eta}_{1}^{\text {Dec.As_Ideal }}=0.50665$} \\
\hline
\end{tabular}

Tabela 3. Exemplo de convergência da NFRes quando a janela de observação cresce em um Descorrelacionador Assíncrono Truncado.

\section{CONCLUSÕES}

Este trabalho de revisão procurou mostrar o potencial incremento na capacidade dos sistemas de comunicação associados às formas fixas de realizaç ão de receptores multiusuário (as)síncronos. Em contraste à detecção Convencional com filtro casado single-user, a detecção multiusuário utiliza as informações dos demais usuários ativos para anular tais sinais que aparecem como MAI quando da detecção do usuário desejado. Em contrapartida ter-se-á um aumento na complexidade de implementação. O receptor DS-CDMA Convencional resulta em capacidade de sistema bem abaixo da capacidade do canal e alta sensibilidade ao efeito near-far, requerendo grandes cuidados com controle de potência e um cuidadoso projeto das sequiências de espalhamento a fim de obter desempenho razoável. Isto têm motivado pesquisas no campo de algoritmos de detecção multiusuário, objetivando reduzir ou mesmo eliminar a MAI. Duas classes de algoritmos para a implementação dos detectores multiusuários subótimos lineares têm sido intensamente estudadas nos últimos anos: o Descorrelacionador e os baseados no erro quadrático médio, como o MMSE; em versões fixas ou adaptativas. No projeto de MUD lineares para sistemas A-CDMA, deve-se observar o compromisso complexidade $(\mathcal{M}) \times$ desempenho, de forma a obter desempenho próximo ao caso síncrono sem incorrer em excessiva complexidade de implementação e atraso de processamento. A seleção e a implementação de receptores CDMA multiusuário constitui uma recente área de pesquisa com várias questões ainda em aberto que garantem a estes receptores um fértil e dinâmico campo de investigação.

\section{AGRADECIMENTOS}

Os autores agradecem aos revisores desse trabalho cujas sugestões permitiram aprimorar a sua apresentação geral.

$\therefore$ No Descorrelacionador One-Shot-1T as correlações são ponderadas peiz energias parciais. No EDAD, decisões são realizadas junto aos bits de For : -mis: à janela de observação. Já o IBI. elimina o efeito dos bits de borda ...serindo um bit de "silêncio" (ausência de informação) no início e final da

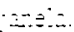




\section{REFERÊNCIAS}

[1.] E. H. Dinan and B. Jabbari, "Spreading codes for direct sequence CDMA and wideband CDMA cellular networks," IEEE Communications Magazine, vol. 36, pp. 48-54, Sept. 1998.

[2] K. H. A. Kärkkäinen and P. Leppänen, "The influence of initial-phases of a PN code set on the performance of an asynchronous DS-CDMA system." Wireless Personal Communications, vol. 13, pp. 279-293, June 2000.

[3] V. M. DaSilva and E. S. Sousa, "Multicarrier orthogonal CDMA signals for quasi-synchronous communication systems," IEEE Journal on Selected Areas in Communications, vol. 12. n.5, pp. 842-52, June 1994.

[H] S. Verdú, "Minimum probability of error for asynchronous gaussian multiple-access channels," IEEE Transactions on Iniomation Theory, vol. 32. n.1. pp. 85-96. Jan. 1986.

[5] S. Verdú. "Optimum multiuser asymptotic efficiency," IEEE Transactions on Commnunications, vol. COM-34, n.9, pp. 8907, Sept. 1986.

[6] R. Lupas and S. Verdú, "Linear multiuser detectors for synchronous CDMA channels," IEEE Transactions on Infonmation Theory, vol. 35, n.1, pp. 123-36, January 1989.

[7] S. Verdú and R. Lupas, "Near-far resistance of multiuser detectors in asynchronous channels," IEEE Transactions on Communications, vol. 38, n.4, pp. 496-507, April 1990.

[8] A. Duel-Hallen, J. Holtzman, and Z. Zvonar, "Multiuser detection for CDMA systems," IEEE Personal Communications. pp. 46-58, April 1995.

[9] S. Moshavi. "Multi-user detection for DS-CDMA communi-


$\therefore:-2$


CD.LA." Proceedings of the IEEE, vol. 86, n.7, pp. 1413-35, July 1998.

[11] D. Chen and S. Roy, "An adaptive multiuser receiver for CDMA systems." IEEE Jonmal on Selected Areas in Conmunications, vol. 12, no. 5, pp. 808-16, June 1994.

[12] U. Madhow and M. L. Honig, "MMSE interference suppression for direct-sequence spread-spectrum CDMA," IEEE Transactions on Communications, vol. 42, n.12, pp. 3178-88, Dec. 1994.

[13] S. L. Miller, "An adaptive DS-CDMA receiver for multiuser interference rejection," IEEE Transactions on Communications, vol. 43, n. 2/3/4, pp. 1746-55, Feb./March/April 1995.

[14] G. Xue. J. Weng, T. Le-Ngoc, and S. Tahar, "Adaptive multistage parallel interference cancellation for CDMA." IEEE Journal on Selected Areas in Communications, vol. 17, n.10, pp. 1815-27, October 1999.

[15] T. Abrão and P. J. E. Jeszensky, "Detectores multiusuários para DS-CDMA - canceladores de interferência," Revista da Sociedade Brasileira de Telecomunicações, vol. 16, n.2, pp. 138156. Dezembro 2001.

[16] A. J. Viterbi, "The orthogonal-random waveform dichotomy soft digital mobile personal communications," IEEE Personal Comnunications, vol. 1, no.1, pp. 18-24, 1st Quarter 1994.

[17] S. Verdú, Multiuser Detection. Cambridge University Press, 1998.

[18] R. M. Buehrer. N. S. Correal, and B. D. Woerner, "A comparison of multiuser receivers for cellular CDMA." in Proc. IEEE GLOBECOM, pp. 1571-7, Nov. 1996

[19] S. Verdú. "Computacional complexity of optimum multiuser detection," Algorithmica. vol. 4, pp. 303-12, 1989.

[20] S. Haykin, Adaptive Filter Theory. Prentice Hall, 1996.

[21] G. H. Golub and C. F. Van Loan, Matrix Computations. Johns
Hopkins Univ Press (3rd edition), 1996.

[22] L. Xie, T. S. Short, and C. K. Rushforth, "A family of suboptimum detector for coherent multiuser communication," IEEE Jounnal on Selected Areas in Communications, vol. 8, n.4, pp. 683-90, May 1990.

[23] U. Madhow and M. Honig, "On the average near-far resistance for MMSE detection of DS-CDMA signals with random spreading," IEEE Transactions on Information Theory, vol. 45, $\mathrm{n}$. 6. pp. 2039-45. Sept. 1999.

[24] H. V. Poor and S. Verdú, "Probability of error in MMSE multiuser detection," IEEE Transactions on Information Theory, vol. 43, n. 3 , pp. 858-71, May 1997.

[25] S. Verdú, "Recent progress in multiuser detection," in Proc. 1988 Int. Conf. Advances in Communications and Control Systems, pp. Vol.1 66-77, Oct.1988. Reimpresso em Multiple Access Communications: Foundations for Emerging Technologies, IEEE Press 1993. pages 164-75, N. Abramson, Ed. IEEE Press, New York, 1993.

[26] L. Wei and R. Jana, "Performance bounds for optimum multiuser DS-CDMA systems," IEEE Transactions on Communications, vol. 47, n.2, pp. 185-90, Feb. 1999.

[27] J. Proakis, Digital Communications. McGraw-Hill. 2nd ed. 1989.

[28] T. Myers and M. E. Magana, "An adaptive implementation of "one-shot" decorrelating detector for CDMA communications." IEEE Transactions Circuits Systems II, vol. 44, pp. 7625, Sept. 1997.

[29] S. Wijayasuriya. G. Norton, and McGeehan. "Sliding window decorrelating algorithm for DS-CDMA receivers," Electronics Letters. vol. 28, pp. 1596-98, Aug. 13th 1992.

[30] S. Wijayasuriya, G. Norton, and McGeehan, "A sliding window decorrelating receivers for multiusers DS-CDMA mobile radio networks," IEEE Transactions on Vehicular Technology, vol. 45, pp. 503-21, Aug. 1996.

[31] J. Shen and Z. Ding, "Edge decision assisted decorrelators for asynchronous CDMA channels system," IEEE Transactions on Communications, vol. 47, n.3, pp. 438-45, March 1999.

[32] K. Barton and F.-C. Zheng, "Near-far resistant detection of CDMA signals via isolation bit insertion," IEEE Transactions on Communications, vol. 43, n.2, pp. 1313-17, Feb 1995.

[33] K. Barton and F.-C. Zheng, "On the performance of nearfar resistant CDMA detectors in the presence of synchronization errors," IEEE Transactions on Communications, vol. 43, no. 12, pp. 3037-45, Dec 1995.

[34] M. J. Juntti and B. Aazhang, "Finite memory-length linear multiuser detection for asynchronous CDMA communications," IEEE Transactions on Communications, vol. 45, n.5, pp. 611-22, May 1997

[35] M. Juntti, Multiuser Demodulation for DS-CDMA Systems in Fading Chantels. PhD thesis, Dep. of Electrical Engineering University of Oulu, Finland, Sept. 1997.

Taufik Abrão é graduado, mestre e doutor em Engenharia Elétrica em 1992, 1996 e 2001. respectivamente, pela Escola Politécnica da Universidade de São Paulo. Atualmente é professor adjunto do Departamento de Engenharia Elétrica da Universidade Estadual de Londrina, PR. Comunicações sem fio, sistemas DS/CDMA quasesíncronos e detectores multiusuários para DS/CDMA constituem as principais áreas de pesquisa de seu interesse.

Paul Jean Jeszensky. Nascido em Nancy-França, obteve os títulos de Engenheiro Eletricista, Mestre em Engenharia Elétrica, Doutor em Engenharia Elétrica-Sistemas Eletrônicos e Livre Docente na área de Telecomunicações, pela Escola Politécnica da USP em 1972, 1981, 1989 e 1992, respectivamente. Autor 
de cerca de 40 trabalhos técnicos/científicos, apresentados em Simpósios/Congressos/revistas especializadas, nacionais e internacionais, nas áreas de atuação acima. Professor da EPUSP desde 1978 e em dedicação exclusiva a partir de 1990, na área de Telecomunicaçōes. Coordenador do LCS-Laboratório de Comunicações e Sinais do Departamento de Engenharia de Telecomunicações e Controle da EPUSP, no período de 1995/97 e 1999/2001. General Co-Chairmen do ITS '98-SBT/IEEE International Telecommunications Symposium, realizado em SP. Professor visitante da UPC-Universitat Politécnica de Catalunya (BarcelonaEspanha) em 1995 e da TUB-Technical University of Budapest (Budapest-Hungria) em 2001. Assessor especial da TELESPCelular para a implantação da digitalização na banda A de Telefonia Móvel Celular, em São Paulo, no período de 1997/98. Coordenador dos convênios de cooperação técnica entre a EPUSP e a Ericsson do Brasil, Motorola do Brasil e TELESP - Celular, desde 1999. Suas áreas de interesse para pesquisa incluem: comunicações sem fio em geral, sequiências de código para uso em sistemas DS/CDMA, sistemas DS/CDMA quase-síncronos e detecção multiusuário em DS/CDMA. 